ISSN (print) 0867-2008 / ISSN (online) 239 I-75 I 2

DOI: http://dx.doi.org/10.12775/OM.2018.007

Monika Jakubek-RaCZKowska*

Instytut Zabytkoznawstwa i Konserwatorstwa

Wydział Sztuk Pięknych

Uniwersytet Mikołaja Kopernika w Toruniu

ul. Sienkiewicza 30/32

PL-87100 Toruń

Poland

mracz@umk.pl

\title{
DIE DOMKAPITEL UND BISCHÖFE IM ORDENSLAND PREUSSEN: IDEOLOGIE, RELIGIOSITÄT UND KIRCHENREFORM ANHAND DER BILDLICHEN QUELLEN
}

\section{KEYWORDS}

art history; the Middle Ages; military orders; Teutonic Order; Prussia; spirituality, bishops, iconography

\section{ABSTRACT \\ The Chapters and Bishops of the Teutonic State in Prussia: Ideology, Religiosity and the Church Reform on the Basis of Pictorial Sources}

The paper focuses on the Church elite in Prussia in the context of the formation and development of the common religious identity in the region through the material sources (work of art). In the historic studies there is still no comprehensive research on the spirituality of high clergy and their activity for the shaping and controlling of the lay-people religiosity (popular religion). In the discussion on the inner spiritual model of canons and bishops as well as on the church reform and promotion of the devotio moderna, not only the written archive basis, but also the iconographic (pictorial) sources have to be analyzed. The author shows on the several examples of artworks (both of official and private use) the possibilities of exploitation medieval images in the study on the individual religious needs and exclusive practice of canons (especially: the decoration of private books and the images in the closed oratories and cloister chambers) and on the propaganda threads, realized as

*ORCID: https://orcid.org/o000-0002-7262-8468 
external testimony of religious attitudes, medium of self-presentation and visualization of ecclesiastical ideology in the liturgical spaces of Prussian cathedrals (Marienwerder (Kwidzyn), Konigsberg (Kaliningrad), Kulmsee (Chełmża), Frauenburg (Frombork)) and bishop’s seats (Heilsberg (Lidzbark Warmiński)).

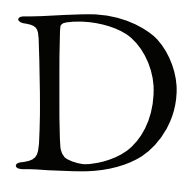
ie Geschichte, Struktur und Tätigkeit der preußischen Domkapitel und Bischöfe sind seit vielen Jahren Gegenstand historischer Studien, von denen die wichtigen Monographien von Mario Glauert ${ }^{1}$ und Radosław Biskup $^{2}$ sowie die Arbeiten von Radosław Krajniak ${ }^{3}$ hervorzuheben sind. Die geistliche Elite, die über die normativen Instrumente verfügte, musste eine Hauptkraft und der Motor für die Gestaltung der religiösen Haltungen der Laien und für ihre Kontrolle sein. Die Bedeutung der preußischen Kirchenhierarchie für die Ausbildung und Entwicklung der allgemeinen religiösen Identität im Deutschordensland waren aber bisher noch nicht Gegenstand einer monographischen Studie. Die Diözese Ermland blieb autonom, die drei anderen der vier preußischen Domkapitel - das kulmische, samländische und pomesanische - wurden noch im I 3. Jh. in den Deutschen Orden inkorporiert. ${ }^{4}$ Die Verpflichtung zum Ordenshabit und zur Einhaltung der Ordensregel bildete eine Voraussetzung sine qua non für die kirchliche Karriere in der Region. Die inneren Beziehungen waren aber von verschiedenem Charakter. Die Aktivität und religiöse Mentalität der Domherren oder Bischöfe kann nicht immer als charakteristisch für den ganzen Deutschen Orden bewertet werden. Trotz einer reichen Archivbasis ist das Problem der Spiritualität dieser wichtigen Kirchengremien, besonders angesichts des Deutschen Ordens, noch offen. In diesem Artikel möchte ich einige Bildquellen des I 4. Jahrhunderts untersuchen, die wichtige Hinweise für weitere historische Studien zu dieser Problematik liefern können.

I Mario Glauert, Das Domkapitel von Pomesanien (1284-I527) (Toruń: Wydawnictwo Naukowe Uniwersytetu Mikołaja Kopernika, 2003); Die Domkapitel des Deutschen Ordens in Preußen und Livland, ed. Radosław Biskup und Mario Glauert, Zeitschrift für die Geschichte und Altertumskunde Ermlands, Beiheft 17 (Münster: Aschendorff, 2004).

2 Radosław Biskup, Das Domkapitel von Samland (I285-I525) (Toruń: Wydawnictwo Naukowe Uniwersytetu Mikołaja Kopernika, 2007).

3 U. a.: Radosław Krajniak, Duchowieństwo kapituty katedralnej w Chetmży do I 466 roku: studium prozopograficzne (Toruń-Łysomice: Europejskie Centrum Edukacyjne, 20 I 3); ders., "Z badań nad biografiami członków warmińskiej kapituły katedralnej w pierwszym okresie jej funkcjonowania (do połowy XIV wieku)," Zapiski Historyczne 80, H. I (20 I 5): 65-83.

4 Andrzej Radzimiński, "Z dziejów kształtowania i organizacji kapituł krzyżackich, Inkorporacje pruskich kapituł katedralnych do zakonu krzyżackiego," in Zakon krzyżacki a spoteczeństwo państwa w Prusach, hrsg. v. Zenon Hubert Nowak, Roczniki Towarzystwa Naukowego w Toruniu 86/3 (Toruń: Towarzystwo Naukowe, I 995), i 23 - I 35. 
Es ist nicht zu bezweifeln, dass die sakralen Bildwerke eine bedeutende Rolle in der breiten religiösen Tätigkeit von geistlichen Eliten spielten. Ihre Funktion hing von der Funktion des Raumes ab und soll vorsichtig differenziert werden: Die Typen der Räume bestimmten den Betrachter, die Betrachter bestimmten die Bildrhetorik. Sie konnte im Rahmen des eigenen religiösen Lebens der Domherren oder im Dienst der Evangelisierung der Laien stehen. Ihr Hauptplatz waren die Kathedralen: die Zentren der elitären Religiosität von Kanoniker, der festlichen Liturgie und Diözesanpatronatskulten, die Pilgerzentren, oft auch - die Ehrennekropolen. In zwei Fällen - Marienwerder und Königsberg - wurden die Domkirchen auch als Pfarrkirchen der Stadtgemeinden genutzt. Das waren die Räume der pastoralen, intellektuellen und Stiftungs-Tätigkeit preußischer Kapitel und Bischöfe. Die dort befindlichen sakralen Bildwerke sind bewusst und absichtlich als Instrumente der religiösen Propaganda benutzt worden. Ihre katechetischen, mnemotechnischen und Devotionsfunktionen wurden in der christlichen Bilddoktrin exakt bestimmt. Die Ausstattungen der Domkirchen standen aber nicht nur mit dem Glauben, sondern auch mit Ehrgeiz und Machtpropanda im Zusammenhang. Nicht selten war eine Imago auch ein Medium der Selbstrepräsentation von geistlichen Eliten, das der Unterstützung ihres Charismas oder Autorität diente.

Das größte Problem der kunstgeschichtlichen Forschung bildet leider der Erhaltungszustand von Kunstwerken: Der heutige Bestand entspricht nicht dem ursprünglichen. Die Bildquellen aus den Domkapitelkreisen sind sehr selten und meistens in sehr schlechtem Zustand erhalten. Wir können kein einziges mittelalterliches Dominneres völlig rekonstruieren. Außer dem Königsberger Dom, der erst im zweiten Weltkrieg zerstört wurde, wurden alle anderen schon in den Kriegen der ersten Hälfte des i 5 . Jahrhunderts stark beschädigt und ihre ältere Ausstattung ging verloren.5 Auch Konfessionswechsel, neuzeitliche Kriege und Res-

5 Die älteste der preußischen Kathedralen - der Dom zu Kulmsee (heute: Chełmża) - wurde noch I 422 von den polnischen Truppen zerstört. Ihr Aufbau dauerte 80 Jahre, von der mittelalterlichen Ausstattung sind nur Reste erhalten. Die Wandmalereien des I 5. Jh.s wurden am Anfang des 20. Jh.s unrichtig übermalt, dann wurden sie bei einem Brand 1950 zerstört. Der Dom zu Marienwerder (Kwidzyn) wurde während der spätmittelalterlichen und neuzeitlichen Kriege beschädigt, im I9. Jh. wurde aber sein Bau stark restauriert und die Wandmalereien irreversibel zweimal übermalt. Der Dom zu Königsberg im originalen Bau existiert nicht mehr: Er wurde völlig während des 2. Weltkrieges zerstört, seine Ausstattung ist nur spärlich dokumentiert. Der Dom zu Frauenburg wurde noch im Mittelalter mehrmals geplündert, im Jahr I 4 I 4, während des I 3-jährigen Krieges und während des Pfaffenkrieges; die Kathedrale wurde am Ende des I 5 . Jh.s erneuert, dann aber noch durch die Schweden beschädigt. Schließlich soll man auch die Stiftskirche in Guttstadt erwähnen, die noch vom Bischof Heinrich Sorbom reich ausgestattet wurde, aber I 4 I 4 zerstört und entehrt wurde. 
taurierungen des 19. Jh.s haben zum Verlust oder zumindest zur Verfälschung des mittelalterlichen Erbes beigetragen. Nur in zwei Schlössern - in Heilsberg (heute: Lidzbark Warmiński) und Marienwerder (Kwidzyn) - sind Teile ihrer mittelalterlichen Ausstattung als Relikte erhalten. Andere bischöfliche Residenzen, die von Marc Jarzebowski erforscht wurden, ${ }^{6}$ sowie die Kapitelsitze sind überhaupt nicht mehr greifbar. Die Tatsache, dass wir nur an Überresten operieren, macht alle Vorschläge hypothetisch.

Die Begrenzungen der kunsthistorischen Analyse gehen aber noch weiter. Trotz der allgemein gebräuchlichen Ikonographie und des geltenden Stilkanons war jedes Bild mit seinem eigenen Code ausgestaltet. Die bildliche Quelle, genauso wie eine schriftliche, muss richtig gelesen und vorsichtig interpretiert werden, was aus heutiger Perspektive nicht immer möglich ist. Die Entschlüsselung ihrer beabsichtigen, primären Inhalte erfordert nicht nur die Kontextkenntnis, sondern auch eine vergleichende Analyse. Nehmen wir als Beispiel das berühmte Epitaph des ermländischen Kanonikers Bartholomäus Boreschow (s. Abb. I). ${ }^{7}$ Als materiellen Gegenstand müssen wir das Epitaph als Beweis der Frömmigkeit betrachten: Es ist ein kostenaufwendiges Votivopfer. Im Geiste des sogen. Schönen Stils wurde hier eine theologische Metapher als Gartenidylle mit dem vor Maria kniender Dekan dargestellt. Sehen wir hier ein reales Bild der inneren Haltung und der privaten Verehrung Boreschows? Es handelt sich um ein öffentliches Bild, das sich im Raum des Frauenburger Domes befand. Wie bei anderen ähnlichen Bildwerken dieser Zeit spielte es seine Rolle im Rahmen von Memoria und Totengebet, aber auch im Kontext des persönlichen Gedenkens. Deshalb ist der Kanoniker mit Porträtzügen, Rangsymbolen, Inschriften und Waffen dargestellt. Seine demütige Genuflexio spiegelt ein universelles Ideal wider; sie ist als äußere Manifestation eines Frömmigkeitsideals in einem bestimmten Bildkanon zu deuten, aber kaum als realer Beweis einer konkreten Frömmigkeitshaltung. Jedes Kunstwerk erfordert also Zurückhaltung in der Beurteilung als historische Quelle.

6 Marc Jarzebowski, Die Residenzen der Preußischen Bischöfe bis Is25 (Toruń: Wydawnictwo Naukowe Uniwersytetu Mikołaja Kopernika, 2007).

7 Zum Bildwerk siehe u. a.: Antoni Romuald Chodyński, "Epitafium Bartholomeusa Boreschowa, ok. pol. XV w.", in Fundacje artystyczne na terenie panstwa krzyżackiego w Prusach. Katalog wystawy w Muzeum Zamkowym w Malborku 25 czerwca - I2 września 20Io roku, hrsg. v. Barbara Pospieszna, Bd. I, Katalog wystawy (Malbork: Muzeum Zamkowe, 20 I0), I92-193; ders., "Portret czy wizerunek paradygmatyczny. Forma i symbolika epitafium Bartholomeusa Boreschowa z około połowy XV wieku," Studia Zamkowe 6 (20 I 2): 27-43. 


\section{IDEOLOGIE}

Beginnen wir mit der ältesten bekannten Domausstattung, die bis zum 2. Weltkrieg im Chorraum in Königsberg erhalten war. Die mittelalterlichen Elemente sind auf die erste Hälfte des I 4. Jh.s zu datieren und mit Bischof Johannes Clare zu verbinden, der persönlich am Bau der Kathedrale mitgewirkt hat. ${ }^{8}$ Nicht ohne Bedeutung ist die Tatsache, dass Clare im engen Kontakt mit dem Hochmeister Luther von Braunschweig stand, der - wie es Simon Helms gezeigt hat ${ }^{9}$ - Interesse an Königsberg als zukünftiger Fürstenhauptstadt hatte und dort begraben worden ist. Die Bauarbeiten am östlichen Teil des Domes verliefen zeitgleich mit dem Umbau der Schlosskapelle in Marienburg. Es ist zu vermuten, dass die deutliche Ähnlichkeit in Architektur und Dekor den Königsberger Chor absichtlich zu einem Raum der Deutschordensideologie gemacht hat ${ }^{10}$ (s. Abb. 2). Sowohl das skulpturale Apostelkollegium an den Wänden sowie der Wandmalereizyklus des Heilsspiegels ${ }^{11}$ sind im Lichte der neuesten Kunstforschungen als Ordenssymbole zu verstehen. ${ }^{12}$ Die Laienkirche mit ihrem Wappenfries ist wiederum nach Werner Paravicini als „Ruhmeshalle des europäischen Adels“ zu bewerten. ${ }^{{ }^{3} 3}$ Im Vergleich zu allen anderen, späteren Kunstwerken ist das ikonographische Programm im Königsberg als Medium einer klaren visuellen Identifizierung des Domkapitels mit dem Deutschen Orden zu verstehen. Aus kunsthistorischer Perspektive (bei heutigem Erhaltungszustand) ist das der einzige Fall.

Aus dem Ende des I 4. Jh.s gibt es schon eine Reihe von Bildwerken, die wahrscheinlich Quellen der bischöflichen Herrschaftsideologie darstellen. Die wich-

8 Eine detaillierte Analyse des Königsberger Chores und seines Dekors siehe: Juliusz Raczkowski, "Die Marien-Aussage der Chorausstattung des Doms zu Königsberg/Pr. vor dem Hintergrund der Ideologie des Deutschen Ordens in Preußen" in Terra Sanctae Mariae. Mittelalterliche Bildwerke der Marienverehrung im Deutschordensland Preußen, hrsg. v. Gerhard Eimer, Ernst Gierlich, Matthias Müller, und Kazimierz Pospieszny, Kunsthistorische Arbeiten der Kulturstiftung der deutschen Vertriebenen 7 (Bonn: Kulturstiftung der deutschen Vertriebenen 2009), I I9-I35; ders., Monumentalne zespoty kolegium apostolskiego na terenie dawnego państwa zakonnego w Prusach (Pelplin: Bernardinum, 20 I 3), I 8 5-20 I.

9 Simon Helms, Luther von Braunschweig. Der Deutsche Orden in Preußen zwischen Krise und Stabilisierung und das Wirken eines Fürsten in der ersten Hälfte des 14. Jabrhunderts, Quellen und Studien zur Geschichte des Deutschen Ordens 67 (Marburg: N. G. Elwert Verlag, 2009), I 58 - I 70 .

10 Raczkowski, “Die Marien-Aussage," passim.

i Besonders: Jerzy Domasłowski, “Dwa przedstawienia średniowiecznego traktatu teologicznego w pomorskim malarstwie ściennym," Rocznik Olsztyński I 6 ( I 989): 27 I-292.

12 Raczkowski, "Die Marien-Aussage," passim.

13 Werner Paravicini, Die Preußenreisen des europäischen Adels, Tl. I, Beihefte der Francia I 7/I (Sigmaringen: Deutsches Historisches Institut Paris, I988), 340-342. 
tigsten kommen aus dem ermländischen Kreis und sind im Bischofsschloss in Heilsberg erhalten. Weil wir keine anderen mittelalterlichen Bischofssitze kennen, ist dieser Bau der einzige Beleg vom bischöflichen Hofzeremoniell, und seine Ausstattung wird in der Literatur als Beweis für die Autonomie, die Rivalität mit dem Deutschen Orden und die Herrschaftspropaganda (Unmittelbarkeit und Unanfechtbarkeit der Macht) der ermländischen Bischöfe betrachtet. Die Überreste des Bilddekors können - nach der Interpretation von Marian Dygo, ${ }^{14}$ Marc Jarzebowski, ${ }^{15}$ Elżbieta Pilecka ${ }^{16}$ - als die Zeugnisse einer solchen Haltung betrachtet werden. Es muss aber unterstrichen werden, dass die erhaltenen Heilsberger Wandmalereien nicht viel mit offener Machtpropaganda zu tun haben sie sind mehr im Zusammenhang mit elitärer Selbstrepräsentation des Bischofsamtes vor elitären Gästen zu verstehen. Die Marienkrönung im Großen Remter kann man natürlich als Gegenpropaganda interpretieren, was in der Forschung auch vorkommt. ${ }^{17}$ Es muss aber hervorgehoben werden, dass der Deutsche Orden kein Monopol für diese sehr populäre Mariendarstellung besaß (die Marienburger Marienkrönung im Großen Remter ist im Lichte der neuesten Forschungen auch viel später zu datieren ${ }^{18}$ ). In einer solcher ikonographischen Auffassung ist die Marienkrönung eine alte Schöpfung der bischöflichen Ekklesiologie, deren Wurzeln bis ins I 2. Jh. reichen. ${ }^{19}$ Man kann vermuten, dass dieses Wandbild nicht als Polemik gegen den Deutschen Orden gedacht war, sondern als eine episkopale Rezeption der westeuropäischen Kirchenallegorie. In ähnlichem Sinn kann man auch die etwas spätere Bischofsgalerie im sogen. Sommerremter interpretieren. Die Ähnlichkeit mit der Galerie der Hochmeister im Winterremter in Marien-

I4 Marian Dygo, "O kulcie maryjnym w Prusach Krzyżackich w XIV-XV wieku," Zapiski Historyczne 52, H. 2 (1987): 2 I-22.

is Jarzebowski, "Die Residenzen," 99.

${ }_{16}$ Elżbieta Pilecka, "Splendor władzy w średniowiecznej rezydencji biskupów warmińskich" in Sztuka w kręu wtadzy. Materiaty LVII Ogólnopolskiej Sesji Naukowej SHS poświęconej pamięci Profesora Szczesnego Dettloffa (I987-I96I) w I30 rocznice urodzin, Toruń 13-Is listopada 2008, hrsg. v. Elżbieta Pilecka und Katarzyna Kluczwajd (Warszawa: Stowarzyszenie Historyków Sztuki, 2009), 53-75.

17 Dygo, "O kulcie," 22.

I8 Sowohl anhand der stilkritischen Analyse, als auch aufgrund der historischen Bedingungen ist es zu vermuten, dass die Wandmalerei über dem Portal im Großen Remter in der Zeit von Konrad von Jungingen, um I 400, ausgeführt wurde. Siehe: Monika Jakubek-Raczkowska und Juliusz Raczkowski, "Średniowieczny wystrój zespołu Wielkiego Refektarza na Zamku Średnim w Malborku” in Wielki Refektarz na Zamku Średnim w Malborku. Dzieje - wystrój konserwacja, hrsg. v. Janusz Trupinda (Malbork: Muzeum Zamkowe, 20 I o), 63-66.

19 Zur Ekklesiologie dieser Szene v. a.: Marie-Louise Thérel, À l'origine du décor du portail occidental de Notre-Dame de Senlis: Le triomphe de la Vierge-Église. Sources historiques, littéraires et iconographiques (Paris: ed. du C.N.R.S, I 984). 
burg aus derselben Zeit scheint offensichtlich. Jedoch kann man in Heilsberg auch an eine bischöfliche Tradition denken, die schon von Ravenna (San Apollinare in Classe $^{20}$ ) und dem ottonischen Trier (Egbert Psalter ${ }^{21}$ ) ausging und sich im I 4. Jh. am besten in dem Bildprogramm der Domchorschranke in Köln realisierte. ${ }^{22}$ Wir haben es hier nicht mit einer neuen lokalen Ideologie zu tun, sondern - nochmal - mit der Rezeption von allgemeinen ehrgeizigen episkopalen Vorbildern. Ein interessantes Motiv bildet die symbolische Darstellung der Errichtung der Diözese (s. Abb. 3): Der erste Bischof Anselm kniet vor Maria mit dem Kind, das als Attribut eine Schriftrolle hält, was an die byzantinische Paraklesis-Bildern erinnert. Alle diese Bildquellen zeugen von der Reifung der Vorstellung des Bischofsamtes mit seinen traditionellen Dignitätszeichen.

Ähnliche Bildzeugnisse sind im pomesanischen Erbe zu finden. Das Mosaik des Johannes Mönch über dem Hauptportal des Doms in Marienwerder, das in Verbindung mit der berühmten Prager Goldenen Pforte von Karl IV. steht, ${ }^{23}$ zeigt den Bischof angesichts seines Patrons, des Hl. Johannes (s. Abb. 4). Hier könnte man über Machtpropaganda und die Erinnerung an seine Person sprechen, aber auch über Selbstrepräsentation der ganzen Ecclesia Pomesaniensi. Der Bischof - in genuflexio dargestellt - verehrt hier den Patron der Diözese und der Domkirche, deren Fragment man an der rechten Seite sehen kann. Das Gebet des Johannes Mönch in einer transzendenten Sphäre scheint eine Fürbitte zu sein, was den Rang des Bischofsamtes hervorhebt. Diese adoratio stellt dabei das Bild in den Rahmen der imitatio pietatis ein: es hat also eine kommunikative Wirkung auf alle, die die Kirche betreten.

20 Die Apsismosaik mit den Bischöfen von Ravenna: Severus, Ursus, Ecclesius und Ursicinus, 6 Jh. Zum bischöflichen Programm der Basilica letztens: Carola Jäggi, "Ravenna in the Sixth Century: the Archaeology of Change," in Ravenna. Its Role in Earlier Medieval Change and Exchange, hrsg. v. Judith Herrin und Jinty Nelson (London: University of London, Institute of Historical Research, 2016), 106-108.

21 Codex Gertrudianus / Psalterium Egberti, zugegriffen am 8. November 20 i 8, http://www.librideipatriarchi.it/en/egberts-psalter-codex-gertrudianus/ (Ende des ı o. Jh.s. Miniaturen mit 14. Trierer Bischöfen und Erzbischöfen). Im Kontext des bischöflichen Bildprogramms in Trier um 980 siehe: Thomas Head, "Art and Artifice in Ottonian Trier," Gesta 36, H. I ( I 997): 73.

22 Die Darstellungen von 62. Kölner Bischöfen und Erzbischöfen an den Innenseiten der Chorschranken, Mitte des I 4. Jh.s, vgl. Herbert Rode, "Die Chorschrankenmalereien des Kölner Domes als Abbild des Sacrum Imperium," Kölner Domblatt 6-7 (1952): 20-38.

23 Barbara Pospieszna, "Z piasku i popiołu Kegin unser libin frouwin bilde. Sztuka mozaiki w państwie zakonnym w Prusach," in Monumentalna figura Madonny na kościele NMP w Malborku. Konteksty historyczne, artystyczne i konserwatorskie, hrsg. v. Janusz Hochleitner (Malbork: Muzeum Zamkowe, 201 5), I09-I I0. 
Nochmals begegnen wir einer solchen Selbstpräsentation in den mit Bischofswappen verzierten Bildern des sogen. Dorotheenschreins ${ }^{24}$ : ein auf dem europäischen Vordergrund einzigartiges Kunstwerk, dessen echte Funktionen unklar bleiben. ${ }^{25}$ Das Werk war bis zum Ende des 19. Jh.s in sehr schlechten Zustand erhalten, ${ }^{26}$ dann wurde es stark restauriert (die Form scheint also nicht völlig original zu sein), während des 2. Weltkriegs ging der Schrein vollständig verloren die heutigen analytischen Möglichkeiten sind also sehr begrenzt. Das ganze Bildprogramm, in dem die Hagiographie und Kreuzlegende mit mariologischen und eucharistischen Inhalten kombiniert wurde, ist vielleicht mit dem liturgischen Kalender zu assoziieren. ${ }^{27}$ Im oberen Register des offenen Schranks waren narrativen Szenen dargestellt, die in dieser Zusammenstellung mit dem Deutschen Orden verbunden werden können - Marienkrönung, Kreuzauffindung, Die Verherrlichung des Kreuzes, Die Rittereucharistie. Im unteren Teil zweimal wurde der Bischof Johannes Mönch im pontifikalen Gewand und mit Insignien dargestellt,

24 Eingehende Beschreibung: Monika Jakubek-Raczkowska, Tu ergo flecte genua tua. Sztuka a praktyka religijna świeckich $w$ diecezjach pruskich państwa zakonu krzyżackiego do potowy XV wieku (Pelplin: Bernardinum, 20 I4), 408-4I 2.

25 Es diente vielleicht der Eucharistieverehrung und/oder Reliquienaufbewahrung. Schon von Johannes Heise wurde es als Reliquienschrank interpretiert, vgl. Die Bau- und Kunstdenkmäler der Provinz Westpreußen, bearb. v. Johannes Heise, Bd. XI, Die Bau- und Kunstdenkmäler des Kreises Marienwerder östlich der Weichsel (Danzig: Commissions-Verlag, i 898), 83. Labuda und Nowiński haben die eucharistischen Funktionen akzentuiert: Adam S. Labuda, "Malarstwo tablicowe państwa krzyżackiego drugiej połowy XIV wieku“ in Jerzy Domasłowski, Alicja Karłowska-Kamzowa, und Adam S. Labuda, Malarstwo gotyckie na Pomorzu Wschodnim (Warszawa-Poznań: Państwowe Wydawnictwo Naukowe, 1990), 82-84; Janusz Nowiński, Ars Eucharistica. Idee, miejsca i formy towarzyszace przechowywaniu eucharystii w sztuce wczesnochrześcijańskiej i średniowiecznej (Warszawa: Neriton, 2000), i 85-186. Einige Forscher, u. a. letztens Stefan Samerski, "Dorothea und kein Ende. Zur Prozess- und Kultgeschichte von Dorothea von Montau," in Cura animarum. Seelsorge im Deutschordensland Preußen, hrsg. v. Stefan Samerski (Köln-Weimar-Wien: Böhlau, 2013), 203, vermuten, dass es um den zukünftigen Dorotheenschrein ging, was aber offen mit dem Bildprogramm des Werkes im Widerspruch steht (die Inhalte sind kaum mit Dorotheas Vita oder Mystik zu verbinden).

26 Die Bau- und Kunstdenkmäler, XI, hrsg. v. Heise, Tafel I 5.

27 Jakubek-Raczkowska, Tu ergo flecte genua tua, 4 I o. Die einzelnen Szenen bilden keine narrative Reihe, weshalb das ganze ikonographische Programm unklar bleibt. Vielleicht ist die Sequenz mit der pomesanischen Liturgie zu erklären. In den Synodalstatuten von Johannes Ryman ( I 4 I I) sind u.a. die Feste berücksichtigt, denen die Ikonographie des Schreins entsprechen könnte: Verkündigung an Maria (Verkündigung), Ostern (Letztes Abendmahl, Ungläubige Thomas), Hl. Kreuzerfindung (Die Kreuzerfindung), Dornenkrone (Arma Christi), Hl. Leichnam (Hostienverehrung, Schmerzensmann), Hl. Kreuzerhöhung (Kreuzverehrung von Heraklius), Hl. Johannes des Taufers, Hl. Johannes Evangelist (beide Szenen mit kniendem Bischof), Hl. Thomas (Ungläubige Thomas), Maria Himmelfahrt (Marienkrönung). "Die pomesanischen Diözesansynoden," Pastoralblatt für die Diözese Ermland 30, Nr. 3 ( 1898): 54. 
der den auferstandenen Christus und die thronende Maria mit dem Kind verehrt. Seine Verbindung mit den unteren Szenen war wahrscheinlich als eine überlegte Kommunikation gedacht: Vor den Augen der Laien erscheint der Bischof als Begleiter der Heiligen und Augenzeuge der wahren Inkarnation und wahren Auferstehung Christi. Die Kirchenlehre ist hier in seiner Person verkörpert. Im Allgemeinen ist dieses Kunstwerk sehr intellektuell, trotzdem konnte es einfachen pastoralen Zwecken gedient haben und mit Gebeten für Bischof ${ }^{28} \mathrm{im}$ Zusammenhang stehen.

\section{KirCHENREFORM}

Die Analyse historischer Gegebenheiten erlaubt, eine solche Programmatik, die als mnemotechnisches Instrument gedacht war, in einen Zusammenhang mit der intensiven Evangelisierungstätigkeit zu stellen. Die Zunahme von pastoralen Handlungen war an der Wende des I 4. zum I 5. Jh. für alle preußische Domkapitel charakteristisch und kann wohl als Einfluss der Prager devotio moderna betrachtet werden. Die böhmische Bewegung mit solchen Autoritäten wie Konrad Waldhausen († I 369), Johann Militsch von Kremsier (Jan Milíč z Kroměříže († I 374)), Adalbertus Ranconis de Ericinio (Vojtěch Raňkův z Ježova ( $\left.\dagger_{\text {I }} 388\right)$ ), Matthias von Janov (Matěj z Janova († I 393)), Heinrich Totting de Oyta († I 396$)$ und Matheus von Krakau (Mateusz z Krakowa ( I $\left._{4} \mathrm{I} \mathrm{O}\right)$ ), war an einer klerikalen Reform interessiert und forderte die pastorale Erneuerung. ${ }^{29}$ Sie betonte ein vertieftes

28 Ein solches Gebet ist in den Sinodalstatuten von Johannes Ryman ( I 4 I I ) aufgenommen: Item volumus, quod in omnibus missis sine nota, in collectis ultimis secretis et complendis dicatur: »et famulum tuum antistitem nostrum cum omnibus sibi commissis ad omni adversitate custodi«. Sacerdotibus hec facientibus et laycis cum tribus oracionibus dominicis et totidem angelicis salutacionibus Deum pro nobis deprecantibus decem dies indulgenciarum de iniunctis sibi penitenciis in Domino relaxamus, vgl. "Die pomesanischen Diözesansynoden," 54.

29 Zum Thema und zur Diskussion über die Prager devotio moderna siehe u. a.: Edouard Winter, Frühhumanismus. Seine Entwicklung in Böhmen und deren europäische Bedeutung für die Kirchenreformbestrebungen im 14. Jahrhundert (Berlin: Akad. Verlag, 1964); Marian Borzyszkowski, "Wczesny humanizm w Czechach a devotio moderna," Rezension von Frühhumanismus. Seine Entwicklung in Böhmen und deren europäische Bedeutung für die Kirchenreformbestrebungen im I4. Jahrbundert von Edouard Winter, Studia Warmińskie 4 ( 1967): 359-362; Jadwiga Krzyżaniakowa, "Henryk Totting z Oyty i jego prascy uczniowie," Roczniki Historyczne 6I (1995): 87-I09; Włodzimierz Bielak, Devotio moderna w polskich traktatach duszpasterskich powstatych do potowy XV wieku (Lublin: Wydawnictwo KUL, 2002); Paulína Rychterová, "Konzepte der religiösen Erziehung der Laien in spätmittelalterlichen Böhmen. Einige Überlegungen zur Debatte über die sog. böhmische Devotio moderna," in Kirchliche Reformimpulse des I4./IS. Jahrbunderts in Ostmitteleuropa, hrsg. v. Winfried Eberhard und Franz 
Engagement der Laien in der religiösen Praxis und bevorzugte den affectus devotionis als Ideal für unmittelbare Beziehung zu Gott. Die böhmischen Gedanken wurden in Preußen sowohl dank der Prager Ausbildung vieler Geistlicher ${ }^{30}$ und der unmittelbaren Kontakte zum Prager Milieu, ${ }^{31}$ als auch durch Vermittlung von Büchern ${ }^{32}$ bekannt. Der berühmteste Vertreter dieser Strömung in Preußen war offensichtlich der pomesanische Dekan und Theologe, Johannes Marienwerderer $\left(\dagger_{14}\right.$ I 7$) .{ }^{33}$ Die Kirchenkrise um 1400 und ein starker Prager Einfluss verursach-

Machilek (Köln-Weimar-Wien: Böhlau, 2006), 2 19-238; Jana Nechutová, "Reform- und Bußprediger von Waldhauser bis Hus," in Kirchliche Reformimpulse des I4./IS. Jahrbunderts in Ostmitteleuropa, hrsg. v. Winfried Eberhard und Franz Machilek (Köln-Weimar-Wien: Böhlau, 2006), 239-254; František Šmahel, "The Faculty of Liberal Arts I 367-I 4 I 9," in František Šmahel, Die Prager Universität im Mittelalter / The Charles University in the Middle Age. Gesammelte Aufsätze / Selectet Studies, Education and Society in the Middle Ages and Renaissance 28 (Leiden-Boston: Brill, 2007), 2 I 3-3 I 5 . Letztens: Martin Dekarli, "Henry Totting of Oyta and the Prague Nominalis Schola Communis between 1366-1409: A Preliminary Draft," in The First Decades of Prague University: Transforming Intellectual Space in $14^{\text {th }}$ Century Central Europe, hrsg. v. Jan Odstrčilík, Francesca Battista, und Riccardo Burgazzi (Prague: Karolinum Press 2016), 53-70. Im breiten europäischen Kontext auch: Die „Neue Frömmigkeit“ in Euro$p a$, hrsg. v. Marek Derwich und Martial Staub, Veröffentlichungen der Max-Planck-Institut für Geschichte 205 (Göttingen: Vandenhoeck \& Ruprecht, 2004).

30 Sieben der zwölf Domherren des pomesanischen Domkapitels um I 400 studierten zuvor in Prag (Glauert, Das Domkapitel, 287-288); wo auch beispielweise Johannes Marienau - späterer Kulmer Bischof - ausgebildet war, wie auch Nikolau Gerkow (von I387), Nikolaus Goldaw (1389) und Nikolaus von Tuchel aus dem Kulmer Kapitel: Radosław Krajniak, "Prałaci kapituły katedralnej w Chełmży w okresie krzyżackim (do I 466r.)," in Kościót i duchowiensstwo $w$ średniowiecznej Polsce $i$ na obszarach sasiednich, hrsg. v. Radosław Biskup und Andrzej Radzmiński, Ecclesia clerusque temporibus medii aevi 3 (Toruń: Wydawnictwo Naukowe Uniwersytetu Mikołaja Kopernika, 20 I 3), ros- 108.

31 Mattheus von Krakau war ein Gast in Heilsberg, sein Werk Rationale divinorum operum war dem Bischof Heinrich Sorbom dediziert, vgl. Władysław Seńko und Adam Ludwik Szafrański, "Mateusz z Krakowa i jego dzieło," in Mateusza z Krakowa Opuscula theologica dotyczace spowiedzi i komunii, hrsg. v. Władysław Seńko und Adam Ludwik Szafrański, Textus et studia. Historiam theologiae in Polonia excultae spectantia II/I = Materiały do historii teologii średniowiecznej w Polsce I (Warszawa: Akademia Teologii Katolickiej, I 974), 25.

32 Die Schriften der Prager Reform sind in der Bibliothek der Thorner Franziskaner (Postilla studentium Pragensium von Waldhausen) oder im St. Elisabeth Hospital in Danzig (Summa dominici ad magistri Henrici de Oyta..., Sermones de tempore et de sanctis und Item sermo Miicii de passione domini von Johann Militsch) zu finden; vgl. Wiesława Kwiatkowska, "Średniowieczna biblioteka klasztoru franciszkanów w Toruniu," Folia Toruniensia I (2000): 2 I; Piotr Oliński, "Bücherliste aus dem Inventar des St. Elisabeth-Hospitals in Danzig. Analyse eines Quellenfragments," in Quellen kirchlicher Provenienz. Neue Editionsvorhaben und aktuelle EDV-Projekte, hrsg. v. Helmut Flachenecker und Janusz Tandecki (Toruń: Towarzystwo Naukowe, 20 I I), I67-169. Einige Texte der Prager Reform sind auch im Kreise der Domkapiteln zu finden: siehe weiter.

33 Zur theologischen Arbeiten Johannes Marienwerder siehe die Primärstudien von Marian Borzyszkowski, "Problematyka filozoficzna i teologiczna w twórczości Jana z Kwidzyna 
ten wahrscheinlich eine episkopale Reformbemühung, die sich in vielen offiziellen Handlungen und normativen Akten widerspiegelt (die schriftlichen Quellen sind in dieser Hinsicht zahlreich). ${ }^{34}$ Die Reformforderung ist auch in einer Synodalpredigt von I 427 spürbar, die dem Kulmer Bischof Johannes Marienau zugeschrieben wird. ${ }^{35}$ Die Reformtätigkeit bezeugen auch konkrete Schriften von Johannes Merkelin $^{36}$ und Johannes Marienwerder, ${ }^{37}$ die sicherlich pastoralen Zwecken dienten. Man hat nachdrücklich Wert auf Predigt, Beichte und Buße gelegt. In einem pomesanischen Gebrauchskodex (jetzt in der Universitätsbibliothek in Toruń) finden wir zum Beispiel eine Sammlung von Texten, die wahrscheinlich als Hilfsmittel für solche Tätigkeiten benutzt wurden..$^{38}$ Johannes de Grottkau, Dekan des samländischen Kapitels von 142 I, besaß einen Kodex mit der berühmten Postille

(1 343-I 417)," Studia Warmińskie 5 (I 968): I I I-I 99 (erster Teil) und ders., "Problematyka filozoficzna i teologiczna w twórczości Jana z Kwidzyna ( I 343-I 4 I 7). Dokończenie," Studia Warmińskie 6 (1969): 85-171.

34 Man kann z. B. die drei Sammlungen von Diözesanstatuten des Bischofs Sorbom in Ermland (1 373-140I), Monitorium in Riesenburg (heute: Prabuty) (1 378) und die Visitationen und Diözesansynode (I 4 I I) in Pomesanien nennen.

35 Johannes Marienau, "Sermo in. conc. prov. Elbingensi (Potentia patris regat...)," in Otto Günther, "Eine Predigt vom preußischen Provinzialkonzil in Elbing 1427 und die Ermahnung des Carthäusers," Zeitschrift des Westpreußischen Geschichtsvereins 59 ( I 919): 94- I I I. Zum Thema der Identität des Autors siehe Marcin Sumowski, "Jan Marienau biskup chełmiński ( I 4 I6- I 457)," Komunikaty Mazursko-Warmińskie 3/273 (20 I I), 506-507.

36 Es sind vor allem Liber de instructione simplicium sacerdotium ad Henricum episcopum Warmiensem und Expositio seu postilla super epistole dominicales zu nennen, vgl. Jan Merkelin, Liber de instructione simplicium sacerdotium, Tl. I-2, hrsg. v. Marian Borzyszkowski, Textus et studia. Historiam theologiae in Polonia excultae spectantia XII/ - -2 (Warszawa: Akademia Teologii Katolickiej, 1982). Siehe auch Franz Hipler, Bibliotheca Warmiensis oder Literaturgeschichte des Bistums Ermland, Bd. I, Abriss der Ermländischen Literaturgeschichte nebst dem Spicilegium Copernicanum, Monumenta Historiae Warmiensis IV (Braunsberg-Leipzig: Eduard Peter, I 872).

37 Vor allem die pastoralen Texten Johannes Marienwerders: Expositio in symboli apostolorum und Beichtbüchlein C. Siehe: Jan z Kwidzyna, "Prolog do Expositio symboli apostolorum", hrsg. v. Marian Borzyszkowski, Textus et studia. Historiam theologiae in Polonia excultae spectantia II/2 = Materiały do historii teologii średniowiecznej w Polsce 2 (Warszawa: Akademia Teologii Katolickiej, I 974), 5-38; vgl. auch Marian Borzyszkowski, "Komentarz do Prologu Expositio Symboli Apostolorum Jana z Kwidzyna," in ebd., 39-6r; und Hans Westpfahl, "Beichtbüchlein des Deutschen Ordens," in Acht Jahrbunderte Deutscher Orden in Einzeldarstellungen. Festschrift für Marian Tumler, hrsg. v. Klemens P. Wieser, Quellen und Studien zur Geschichte des Deutschen Ordens I (Bad Godesberg: Verlag Wissenschaftliches Archiv, I967), 24I-268.

38 Cod. Silva Rerum, i 398, Toruń, Biblioteka Uniwersytecka, Rps 3/I, vgl. Katalog rękopisów średniowiecznych Biblioteki Uniwersyteckiej w Toruniu, hrsg. v. Marta Czyżak, unter Mitwirkung v. Monika Jakubek-Raczkowska und Arkadiusz Wagner (Toruń: Wydawnictwo Naukowe Uniwersytetu Mikołaja Kopernika, 20 I6), I 2- I9. Unter anderen Texten sollen in diesem Kontext folgende genannt werden: die Statuten von Johannes Mönch (fol. 5 I r-53v), Ps.-Bernardus Claraevallesis, Formula honeste vitae (fol. 57r-6ov), Gute Beichte (fol. 84r), Morale Indizien (fol. 
Konrads von Waldhausen (das Buch wurde von dem Benutzer mit vielen Glossen versehen).39

Der religiöse Charakter der devotio moderna, die durch mystische Gedanken von Tauler und Seuse beeinflusst war, ${ }^{40}$ verursachte auch ein lebhaftes Interesse an Individualisierung von religiöser Erfahrung und Kult. In seinen Texten hat Johannes Marienwerder zweimal einen Aufruf: Expergiscimini hodie anime devote wiederholt ${ }^{41}$ („Weckt die frommen Seelen auf!“). In den Ablassbriefen dieser Zeit ist die neue Formulierung causa devotionis zu finden. ${ }^{42}$ Ein Kulminationspunkt dieser Tätigkeit waren sicher die öffentliche Promotion des Frömmigkeitsideals Dorotheas von Montau ${ }^{43}$

93v), Ps.-Bonaventura, Instructio sacerdotis ad se preparandum ad celebrandum missam ( $124 \mathrm{r}-$ - I27v), Aufzählung von Sünden und Tugenden (128r-130v).

39 Conradus de Waldhausen, Postilla studentium sanctae Pragensis universitatis, I 396, Toruń, Biblioteka Uniwersytecka, Rps 38/III; vgl. Katalog, hrsg. v. Czyżak, I 5 6- I 59.

40 Über Taulers Einfluss auf die Schriften von Johannes Marienwerder: Stefan Kwiatkowski, "Wpływ doktryny Jana Taulera na hagiograficzną sylwetkę Doroty z Mątowów w piśmiennictwie Jana z Kwidzyna," in Balticum. Studia z dziejów polityki, gospodarki i kultury XII-XVII wieku ofiarowane Marianowi Biskupowi w siedemdziesiata rocznice urodzin, hrsg. v. Zenon $\mathrm{Hu}-$ bert Nowak (Toruń: Wydawnictwo Towarzystwa Naukowego, I 992), I 89-1 96.

${ }^{41}$ Die Apostrophe Expergiscimini hodie anime devote, amatrices vere devote crucifixi et vigilanter attendite et videte opera domini, que posuit super terram stand auf dem Anfang der Prager Synodalpredigt Johannes Marienwerders (1 384) und wurde später in seinem Traktat Expositio symboli apostolorum wiederholt. Borzyszkowski, "Problematyka filozoficzna," ( I 968), I 22.

42 Zum Beispiel Ablassbrief des Kulmer Bischofs Arnold ( $14 \mathrm{I}$ ), vgl. Urkundenbuch des Bisthums Culm, Bd. I, Das Bisthum unter dem Deutschen Orden I243-I466, hrsg. v. Carl Peter Woelky, Neues Preussisches Urkundenbuch. Westpreussischer Theil, II. Abtheilung: Urkunden der Bisthümer, Kirchen und Klöster I (Danzig: Commissionsverlag von Theodor Bertling, I 885), 37 I Nr. 48; auch päpstliche Ablassbriefe aus dem Ende des I 4. Jh.s, für Ermländische Kirchen Guttstadt (heute: Dobre Miasto), Frauenburg (Frombork), Lockau (Tłokowo): Codex Diplomaticus Prussicus. Urkunden-Sammlung zur ältern Geschichte Preussens aus dem Königl. Geheimen Archiv zu Königsberg nebst Regesten, Bd. III, hrsg. v. Johannes Voigt (Königsberg: Gebrüdern Vornträger, I 848), 232-233 Nr 26I; 234-235 Nr 264; 233-234 Nr 263; 37 I Nr 383.

43 Die Dorotheas Mystik ist dank der Schriften von Johannes Marienwerder gut bekannt, unter denen vor allem eine "mystische Trilogie" - Liber de festis, Septilillium und Vita latina - zu nennen sei. Siehe: Liber de festis Magistri Johannes Marienwerder. Offenbarungen der Dorothea von Montau, hrsg. v. Annelise Triller, unter Mitwirkung Ernst Borchert, nach Vorarbeiten von Hans Westpfahl (Köln-Weimar-Wien: Böhlau, 1992), Septililium Beatae Dorotheae Montovensis auctore Joanne Marienwerder, hrsg. v. Franciscus Hipler, Analecta Bollandiana, Bruxelles I 885; Vita Dorotheae Montoviensis Magistri Johannis Marienwerder, hrsg. v. Hans Westpfahl, unter Mitwirkung Anneliese Triller (Köln-Graz: Böhlau, 1964). Es ist offensichtlich, dass die Johannes Marienwerders Erfassung eine eigene intellektuelle Interpretation der mystischen Erfahrung der Rekluse war. Über verschiedenen Aspekten seinen Auslegung au niveau der Visionen und körperlichen Leidens Dorotheas, vgl. Monika Jakubek-Raczkowska, "Mentis oculos levavit. Obrazowe aspekty mistyki Doroty z Mątów," Studia Elbląskie I 4 (2013): 289-306; 
und dann ihr Heiligsprechungsprozess, ${ }^{44}$ an dem die Vertreter aller Domkapitel beteiligt waren. ${ }^{45}$ Besonders für die pomesanischen Domherren wurde Dorothea zum Symbol der Spiritualität und ein Motor ihrer Karriere.

Obwohl wahrscheinlich das Marienwerdersche Domkapitel den größten Anteil an der Reformtätigkeit hatte, finden wir die beste bildliche Quelle für die ganze Programmatik im Heilsberger Schloss. Im zweiten Stock des Schlosskreuzganges wurden evangelische Darstellungen und Heiligenbilder von einer böhmischen Werkstatt Prager Provenienz gemalt, ${ }^{46}$ die in ihrer Ikonographie einen besonderen Beweis für devotio moderna geben. Von diesen Wandmalereien ist v. a. die Reihe im westlichen Flügel zu nennen. Sie beginnt mit dem Zwölfjährigen Christus im Tempel - was in Kontext der Lehre und Evangelisierung zu verstehen ist - und wird dann zu einer episkopalen „Reformmetapher" entwickelt: bildliche Instruktion für den Klerus. In dieser Hinsicht sind die Heilsberger Malereien weder gut bekannt noch gut erforscht - sie sind erst nach der neuesten Konservierung lesbar. ${ }^{47}$ Die erste Szene stellt die Heilsbemühung mit einem großen Anteil der Geistlichen dar (s. Abb. 5). Es sind eine Predigt, eine Beichte und die Buße, die sicherlich im Sinne der Compassio Christi mit einer Kreuzverehrungsdarstellung verbunden wurde, zu sehen..$^{8}$ Die nächste, besser erhaltene und deshalb auch in

dies., "Amoris saggitae et spicula. Cielesne aspekty mistyki bł. Doroty z Mątów - próba reinterpretacji," Studia Elbląsie I 5 (2014): I 65- I 87.

44 Die Akten des Kanonisationsprozesses Dorotheas von Montau von I394 bis IS2I, hrsg. v. Richard Stachnik in Zusammenarbeit mit Anneliese Triller und Hans Westpfahl (Köln-Wien: Böhlau, 1978). Vgl. Cordelia Hess, Heilige machen im spätmittelalterlichen Ostseeraum. Die Kanonisationsprozesse von Birgitta von Schweden, Nikolaus von Linköping und Dorothea von Montau, Europa im Mittelalter. Abhandlungen und Beiträge zur historischen Komparatistik I I (Berlin: De Gruyter, 2008), 245-33 I.

45 Die Rolle Dorotheas für die Gestaltung eines offiziellen, von den Kapiteln promovierten Frömmigkeitsmodells habe ich schon anderswo genauer analysiert: Jakubek-Raczkowska, Tu ergo flecte genua tua; zur Bedeutung des Prozesses für Promotion der privaten Religiosität unter Laien: ebd., I I 4-I 19, I 46-I 50, über die Frömmigkeitspraxis in Preußen in diesem Zusammenhang: ebd., I 59-207.

46 Jerzy Domasłowski, "Gotyckie malowidła ścienne krużganku zamku biskupiego w Lidzbarku Warmińskim i ich europejski kontekst," in Zamek malowany. Ratunkowe prace konserwatorskie krużganków zamku lidzbarskiego, hrsg. v. Janusz Cygański (Olsztyn: Muzeum Warmii i Mazur, 20I I), 35-59.

47 Leider sind sie in sehr schlechten Zustand erhalten, und die Details sind im natürlichen Licht kaum erkennbar. Vgl. die Rekonstruktionen von Ryszard Żankowski, "Badania i rekonstrukcja wyglądu oraz treści przedstawień zniszczonych dekoracji malarskich z końca XIV wieku w krużgankach" in Marcin Kozarzewski, Ryszard Żankowski, und Adam Szweda, Polichromie krużganków zamku w Lidzbarku Warmińskim (Olsztyn: Muzeum Warmii i Mazur, 2016), 57-II3.

48 Bildliche Rekonstruktion, vgl. Żankowski, "Badania i rekonstrukcja," i I o- I I I. 
der Literatur besser bekannte Szene zeigt den Erfolg dieser Evangelisierung: Die Laiengruppe kommt in den Himmel unter Leitung ihres Bischofs, der als erster auf der Leiter steht und von Maria und Christus empfangen wird (s. Abb. 6). Die dritte, leider fast unlesbare Szene ist den Konsequenzen von Ablehnung und Missbrauch gewidmet: Die Laien, die den Weg der Kirche verlassen haben und nach Unterhaltung suchen (s. Abb. 7), sind schon verdammt; zwischen Tanzenden und Turnierspielenden sind Teufel zu beobachten. Ähnliche Vorstellungen kann man in den Visionen Dorotheas von Montau im Liber de festis finden; ${ }^{49}$ ein direkter Zusammenhang ist aber leider nicht zu beweisen.

Die Grundvermittlung, die von den Kanzeln in der Reformzeit an die Laien adressiert wurde, ist uns dank der lateinischen und deutschen Dorotheenschriften von Johannes Marienwerder und der Prozessakten gut bekannt. Im Kontext der episkopalen Erneuerung des Kirchenlebens ist die Kritik, die von Christus selbst in Dorotheas Visionen an den Klerus adressiert war, sehr interessant. In der Vita latina und Liber de festis findet man sehr aktuelle Botschaften über Missbräuche und die Notwendigkeit der moralischen Besserung der Geistlichen. Es ist auch offensichtlich, dass die fromme Volksrekluse den Laien als Modell der Frömmigkeit und Heiligkeit vorgestellt wird. Dieses integriert verschiedene exemplarische Haltungen: Eucharistiekult, Buße, Askese, Frömmigkeitsgefühl, Meditationsgebet, Pilgerfahrt, Ablassbemühung, usw. ${ }^{50}$ In der Vita germanica schrieb Johannes Marienwerder, wohl an die Laien:

„Nehmet zu Herzen, ihr andächtigen, treuen Christen, Gottes Ehre, eure Besserung und des Glaubens Bestätigung von dieser seligen Mutter Dorothea [...]. Ihr, frommen Hörer und Leser dieses Buches, prüfet, erwäget und glaubet, dass der Herr [...] in seiner erwählten Braut Dorothea seine gnadenreichen Wunderwerke erneuert hat..51

Die damalige Predigtrhetorik, aus der Vita germanica bekannt, wurde sicherlich durch die Bilder unterstützt. ${ }^{52}$

49 Liber de festis, hrsg. v. Triller, 68 cap. 38: Vidit turbas varigenas, gestus habentes in cantu, saltu, cibo, potu et chorea et alia multa mala nimi grossa.

so Jakubek-Raczkowska, Tu ergo flecte genua tua, I 59-207.

51 Johannes Marienwerder, "Das leben der seligen Dorothea von Preussen," nach der deutschen Lebensbeschreibung des Johannes Marienwerders in neuerer Schriftsprache hrsg. v. Franz Hipler, Zeitschrift für die Geschichte und Alterstumskunde Ermland Io ( I 894): 306.

52 Aus den Quellen wissen wir von Darstellungen von Dorothea und der alten kulmischen Mystikerin Jutta, die sich in der Domkirche in Kulmsee um I 400 befanden; in der Marienwerder Domkirche gab es sicherlich auch solche Bilder, was in den Prozessakten bestätigt wird, die aber leider ebenfalls nicht erhalten sind. In den Wandmalereizyklus in der Domkirche finden wir nur eine grob übermalte Darstellung, die ich mit Vorsicht mit Dorothea verbinden möchte. Zur Ikonographie: Jakubek-Raczkowska, "Mentis oculos levavit," 323-324; vgl. Alicja Grabows- 
Es gibt einige Bildzeugnisse für das Bemühen der Kirchenhierarchie um die Vertiefung der religiösen Erfahrung und um die Hervorhebung der Kulte mit mystischem Hintergrund wie den Passionskult und die Verehrung der Eucharistie, die um I 400 im Deutschordensland schon gut erfassbar werden. Im Dom zu Marienwerder befindet sich z. B. unter vielen Darstellungen, die um I 400 an die Wände des Kirchenschiffs gemalt wurden, ein expressives Altarbild des Vir Dolorum (s. Abb. 8), sowie eine sehr seltene, lukkanische Art der Kreuzigungsdarstellung (Volto Santo) ${ }^{53}$. Im Dom in Kulmsee ist eine Wandmalerei mit Christus an der GeiBelsäule auf dem Pfeiler erhalten, ${ }^{54}$ sowie eine der drei im Ordenslande existierenden"s Andachtsfiguren des Kreuztragenden Jesus mit einem stark emotionalen Ausdruck (s. Abb. 9). Man kann diese Kunstwerke als Beispiele für bildliche Quellen des affectus devotionis in preußischen Domkirchen anführen. Ihre Anwesenheit in diesen liturgischen Räumen ist nicht außergewöhnlich, ${ }^{56}$ sondern für die Religiosität im Ordensland symptomatisch.

\section{RELIGIOSITÄT}

Wie kann man angesichts der offiziellen Tätigkeit die eigene innere Spiritualität der Kanoniker einschätzen? Die Antwort auf diese Frage ist nicht selbstverständlich. Sowohl die schriftliche als auch die bildliche Quellenbasis sind in diesem Zusammenhang nicht sehr reichhaltig. Sicherlich kann man den Wandmalereizyklus im oberen Chor des Domes in Marienwerder im Rahmen der kollektiven Religiosität der Domherren analysieren. Die Darstellungen aus dem I 4. Jh. sind jedoch nur fragmentarisch sichtbar, ${ }^{57}$ weil sie am Ende des 15 . Jh.s mit einer Bi-

ka-Lysenko, "Ikonografia bł. Doroty z Mątów Wielkich," in Kwidzyńska rekluza. Uniwersalne i regionalne przejawy kultu bt. Doroty z Mątów, hrsg. v. Janusz Hochleitner (Kwidzyn: Muzeum w Kwidzynie, 2014), I75-194.

53 Genauer über Wandmalereien im Marienwerder Dom im Kontext von Bildgebrauch und pastoralen Bildrhetorik: Jakubek-Raczkowska, Tu ergo flecte genua tua, 403-408.

s4 Sławomir Majoch, "Rzeźba Chrystusa dźwigającego krzyż z konkatedry w Chełmży. Forma i funkcja," Rocznik Muzeum Okregowego w Toruniu I 2 (2003): 72-91; vgl. neue Interpretation als Trostbild: Jakubek-Raczkowska, Tu ergo flecte genua tua, 388-389.

ss Nebst einer Figurengruppe in St. Thomaskirche in Neumark (Nowe Miasto Lubawskie) und einer nicht mehr vorhandenen Skulptur aus Schwetz (Świecie).

56 Die Dome waren natürlich nicht die einzigen Orte solchen Bildgebrauchs. In dieser Zeit finden wir viele andere, emotionell markierte Bildwerke auch bei den Mendikanten und in einigen Pfarrkirchen in der Region. Zu Andachtsbilder in den Pfarrkirchen um I 400 vgl. Jakubek-Raczkowska, Tu ergo flecte genua tua, 379-391.

57 Juliusz Raczkowski, "Problematyka konserwatorska malowideł w chórze katedry w Kwidzynie w kontekście historycznym oraz w świetle najnowszych odkryć," in Studenci o konserwacji. 
schofsgalerie übermalt worden sind. ${ }^{58}$ Der Zyklus erstreckte sich über den ganzen Innenraum und wurde mit Inschriften ausgestattet. Heute sind nur eine seltene Szene Infantia Christi (s. Abb. 1o) und ein Vir Dolorum zu erkennen. Sicherlich waren die Wandmalereien als ein Meditationsmedium im Dienst des liturgischen Gebets und der außerliturgischen Andacht konzipiert.

Ein weiteres Beispiel im exklusiven Raum finden wir in der vermeintlichen Kanzlei im Marienwerder Schloss. Auf dem Gewölbe wurden vor kurzem figürliche Wandmalereien entdeckt, die dem Raum eine sakrale Stimmung geben und die innere Heiligenkulte des Domkapitels belegen. ${ }^{99}$ Diese Darstellungen sind leider in schlechtem Zustand erhalten, so dass nur die Hl. Dorothea und Jakobus ohne Zweifel identifiziert werden können. Trotz der schlechten Lesbarkeit bilden die beiden Beispiele eine zusätzliche Quelle, die den Bildgebrauch im engeren und geschlossenen Kapitelkreis bezeugt.

Die innere Haltung und eigene Spiritualität der Domherren sind vor allem durch die von ihnen benutzten Texte greifbar und durch die Bilder, die diese Texte begleiten. Dadurch haben die Kodizes in diesem Kontext ein großes Forschungspotential. Die Texte der Mystik und Prager devotio moderna waren in allen Kapitelbeständen zu finden. In dem oben zitierten pomesanischen Gebrauchskodex (Toruń, Biblioteka Uniwersytecka, Rps 3/I) finden wir auch die asketisch-mystischen Schriften ${ }^{60}$ von Pseudo-Bernardus, David von Augsburg, dem Hl. Bonaventura wie auch Malogranatum - ein böhmisches Vorspiel zur mitteleuropäischen devotio moderna ${ }^{61}$ Als ein einzigartiges Beispiel solcher Art sollen aber die vier la-

Materiaty III Ogólnopolskiej Konferencji Naukowej Studentów Konserwacji Zabytków, Toruń, 22-24 lutego $200 \mathrm{I}$ r., hrsg. v. Tomasz Korzeniowski (Toruń: Koło Naukowe Studentów Konserwacji Dzieł Sztuki UMK, 200 I): I 5 I - I 64; ders., "Malowidła ścienne w katedrze w Kwidzynie, 4 ćw. XIV w.," in Fundacje artystyczne na terenie państwa krzyżackiego w Prusach. Katalog wystawy w Muzeum Zamkowym w Malborku 25 czerwca - I2 września 2oIo roku, Bd. I, Katalog wystawy, hrsg. v. Barbara Pospieszna (Malbork: Muzeum Zamkowe w Malborku, 20 Io), I 67.

58 Ausführlicher dazu siehe: Juliusz Raczkowski, "Późnogotyckie malowidła w górnym chórze katedry kwidzyńskiej," Studia Zamkowe 2 (2006): i 8 5-204.

s9 Juliusz Raczkowski, "Medieval murals recently uncovered in the chamber above the gate of the castle of the chapter of the diocese of Pomesania in Kwidzyn: preliminary analysis. Iconography, style, dating and functional role of the chamber," Ordines Militares Colloquia Torunensia Historica. Yearbook for the Study of the Military Orders 22 (2017): 287-304.

60 Cod. Silva Rerum, I 398, Toruń, Biblioteka Uniwersytecka, Rps 3/I, u. a.: David de Augusta, De exterioris et interioris hominis compositione (fol. 6ov-84r), Bonaventura, De triplici via alias incendium amoris (fol. 84v-9Iv), Gallus abbas de Aula Regia, Malogranatum de triplici statu statu religiosorum (abbreviatio) (fol. 98r-I23v), Ps.-Bernardus Claraevallesis, Meditationes de bumana conditione (fol. I I I- I 52r); vgl. Katalog, hrsg. v. Czyżak, I 6-i 7 .

61 Über die Bedeutung von Malogranatum: Manfred Gerwing, “...state in fide vera, viriliter agite, omnia vestra in caritate fiant. Zum dreifachen Weg im Malogranatum,” in Die „Neue 
teinischen Handschriften betrachtet werden, die Eigentum eines samländischen Kanonikers und Dekans, Johannes Albrechtau ( $†$ nach I 4 I I), waren und dann als sein Legat an die Königsberger Dombibliothek kamen. ${ }^{62}$ Sie bescheinigen eine hohe intellektuelle Bildung des Benutzers im Geiste der devotio moderna: ein Silva rerum Prager Provenienz, mit asketischen Texten und Indizien über die Heilige Messe $^{63}$; ein Predigtbuch mit Sermones-Texten ${ }^{64}$; ein Silva rerum ${ }^{65}$ mit verschiede-

Frömmigkeit" in Europa, hrsg. v. Marek Derwich und Martial Staub, Veröffentlichungen der Max-Planck-Institut für Geschichte 205 (Göttingen: Vandenhoeck \& Ruprecht, 2004), 85 - I IO.

62 Alle vier werden heute in der Universitätsbibliothek in Torun aufbewahrt. Zur Albrechtau-Sammlung: Marta Czyżak, "Medieval manuscripts as ego-documents on examples of the prayer book of wikbold dobilstein and the biblical-moralistic collection of Johann Albrechtau in the 4th quarter of the I 4th century," in Editionswissenschaftliches Kolloquium 2013. Neuere Editionen der sogenannten "Ego-Dokumente" und andere Projekte in den Editionswissenschaften, hrsg. v. Helmut Flachenecker, Janusz Tandecki, und Krzysztof Kopiński, Publikacje Niemiecko-Polskiej Grupy Dyskusyjnej do Spraw Edycji Źródeł 7 (Toruń: Towarzystwo Naukowe, 20 I 5 ), I 8-25; dies., "Interdyscyplinarne prace badawcze nad Katalogiem rękopisów średniowiecznych Biblioteki Uniwersyteckiej w Toruniu," in Stare i nowe dziedzictwo Torunia, Bydgoszczy i regionu, hrsg. v. Juliusz Raczkowski und Monika Jakubek-Raczkowska, Studia i materiały z dziedzictwa kulturowego Torunia i regionu 2 (Toruń: Wydawnictwo Naukowe Uniwersytetu Mikołaja Kopernika, 20 I 7), I03.

63 Cod. Silva rerum, I 386 , Toruń, Biblioteka Uniwersytecka, Rps 3 I /III; Inhalt: Ioannes Beleth, Summa de ecclesiasticis officiis (fol. $2 \mathrm{r}-43 \mathrm{v}$ ), Innocentius papa III, De sacro altaris mysterio (fol. $44 \mathrm{r}-88 \mathrm{v}$ ), Ps.-Bernardus Claraevallensis, Meditationes piissimae de cognitione humanae conditionis (fol. 89r-96v), Casus in Summam Henrici minoris de Merseburg (fol. 97r-122v), De compositione astrolabii (fol. I $23 \mathrm{r}-\mathrm{I} 25 \mathrm{r}$ ), Guillelmus de Conchis (?), Moralium dogma philosophorum - abreviatio ( $126 \mathrm{r}-\mathrm{I} 34 \mathrm{r}$ ), Passionsmeditationen (fol. I 34v-137v), Dicta de celebratione missae (fol. I 37v), Ps.-Bonaventura, Tabula ante celebrationem missae consideranda (Vorsatz); vgl. Katalog, hrsg. v. Czyżak, I $22-$ I 29.

${ }_{64}$ Cod. Silva rerum, um I 390, Toruń, Biblioteka Uniwersytecka, Rps 52/III; Inhalt: Gregorius Magnus, Homiliae XL in Evangelia (fol. Iv-86r), David de Augusta OFM, De exterioris et interioris hominis compositione (fol. 86r-149r), Henricus de Frimaria senior OESA, Tractatus de decem praeceptis (fol. I 5or-193v), Sermo bonus de dedicatione templi (193r-199v), Nicolaus Claraevallensis OCist., Sermo de Nativitate s. Ioannis Baptistae (fol. I 99v-204r), Ioannes Balistarii Lemovicensis OP, Sermo de s. Maria Magdalena (fol. 204v-207r); vgl. Katalog, hrsg. v. Czyżak, 2 I 6-22 I.

65 Cod. Silva Rerum, um I 388, Toruń, Biblioteka Biblioteka Uniwersytecka, Rps 75/III; Inhalt u. a.: Petrus Riga, Aurora, ab Aegidio Parisiensi aucta (fol. Ir-86v), Versen- und Zitatensammlung (fol. 86v-87v), Landesverordnung über die Heiligung des Sonntages und Bestrafung unordentlichen Lebens (fol. 87v), Petrus Pictaviensis, Compendium historiae in genealogia Christi (fol. 88r-97r), Honorius Augustodunensis, Gemma animae (fol. 97v-98v), De decem praeceptis (fol. 98r), Genealogie von Jesus (fol. Io Ir-105v), Petrus de Crescentiis, Ruralia commode (fol. 105r-107v), Granum sinapis (fol. 107v), Lat. Kommentar zu Granum sinapis (fol. 107v- I08v), Petrus Comestor, Historia Evangelica, Sieben Sünden (fol. I I 2 r- I 5 Iv), Lex evangelica (fol. I 52r-1 58v), Sieben Sünden (fol. I 59v), Petrus Pictaviensis, Historia libri Actuum Apo- 
nen - auch asketischen Schriften und Versen, besonders mit einem Granum Sinapis ${ }^{66}$ (einem mystischen Lied aus dem Umkreis vom Meister Eckhart), das von dem Dekan selbst kopiert wurde; endlich ein Kommentar des Heiligen Bonaventura zum Johannesevangelium. ${ }^{67}$

Das letzte Buch wurde nach Marta Czyżak wahrscheinlich im Ganzen selbst von Johannes Albrechtau kopiert und selbst von ihm mit Fleuronnée verziert. ${ }^{68}$ Das zeugt von bewusster Auswahl der Inhalte und von der bewussten Nutzung der Bücher. Einen weiteren Beweis dafür liefern die außergewöhnlichen bildlichen Quellen. Drei von diesen Büchern sind mit derselben Hand um die Passionsdarstellungen ergänzt, die mit dem Inhalt der Kodizes kaum in Zusammenhang stehen und nicht zum allgemeinen Verzierungssystem gehören. Es sind leichte, unbeendete Federzeichnungen, mit schwarzer und roter Tinte skizziert. Am Vorderspiegel des Manuskriptes 35/III finden wir eine gute Studie des Gekreuzigten, mit angedeuteten Schatten, nach Vorbildern aus der böhmischen Kunst des letzten Viertels des I 4. Jh.s Ein weiteres ähnliches Bild wurde auf dem Vorderspiegel im cod. 3 I/III ausgeführt. Die Zeichnung ist hier viel einfacher, aber auch stärker in ihrer Passionsauswirkung: Christus ist ganz nackt, was das eucharistische Opfer evozieren soll, und die roten Blutströme wirken sehr expressiv. Die dritte Zeichnung, eine Schmerzensmanndarstellung (s. Abb. I I) - ein echter Andachtstypus im eucharistischen Sinn - befindet sich auf der letzten Seite des cod. 52/III. Die detaillierte Analyse bestätigt die Identität des ziemlich begabten Autors aller drei Zeichnungen. Ihre Stilmerkmale und ikonographischen Vorbilder entsprechen der Entstehungszeit der Manuskripte, man kann also die Ausführung dieser Skizzen wahrscheinlich dem ersten Benutzer selbst zuschreiben. Alle drei Zeichnungen sind keine zufälligen künstlerischen Studien, wie man sie in vielen mittelalterlichen Handschriften finden kann (wie in einem Beispiel aus der samländischen Dombibliothek $\left.{ }^{69}\right)$. Im Gegensatz sind die Kodizes von Albrechtau, mit absichtlichen Bildergänzungen, als Zeugnis einer innigen Passionsfrömmigkeit zu betrachten. In einem ähnlichen privaten Gebrauch wird sich endlich auch das

stolorum (fol. 16or-195rv), Augustinus Hipponenesis, De consensu Evangelistarum libri quatuor - abbreviation (fol. I 95 r-2 I 8v); vgl. Katalog, hrsg. v. Czyżak, 3 I 8-327

66 Ralf Päsler, "Ein neuer Textzeuge des 'Granum Sinapis' aus der Königsberger Dombibliothek," Zeitschrift für deutsches Altertum und deutsche Literatur I 36 (2007): 58-67.

${ }_{77}$ Cod. Bonaventura, Commentarium in Evangelium, I 384 , Toruń, Biblioteka Uniwersytecka, Rps 35/III; vgl. Katalog, hrsg. v. Czyżak, I 40-I 45.

68 Czyżak, "Interdyscyplinarne prace," I 03; Katalog, hrsg. v. Czyżak, I 44.

69 Cod. Johannes Halgrinus de Abbatisvilla, Sermones super psalterium, 2. H. I 3. Jh, Glossae und Zeichnungen um I 400, Toruń, Biblioteka Uniwersytecka, Rps 9/I. 25 Marginalzeichnungen, z. B. fol. I44v (Hl. Margarete), 204v (Salvator Mundi), I 9or (Hl. Katharina); vgl. Katalog, hrsg. v. Czyżak, 34-4I. 
Buch Sermones de tempore aus Königsberg ${ }^{70}$ befunden haben. Hier auch finden wir eine zusätzliche unbeendete Kreuzigungszeichnung, wahrscheinlich von dem Buchbenutzer eingefügt - ein weiteres Zeugnis des Passionsfrömmigkeitsbedarfs, aber auch ein Beleg für die künstlerischen Fähigkeiten im Kreise des samländischen Kollegiums.

\section{SCHLUSS}

Die vergleichende Analyse von Kunstwerken, die als besondere direkte oder mittelbare historische Quellen betrachtet werden, liefert einige Hinweise auf episkopale Ideologie, Reformforderungen und auch innere religiöse Haltung der höchsten geistlichen Eliten in Preußen. Zusammen mit den schriftlichen Quellen können die Bilder als wichtige Dokumente - zumindest für Ideologie und Frömmigkeitsstrategien der preußischen Kirchenhierarchie - erkannt werden. Die Frage nach der Identität und dem Selbstbewusstsein der Domkapitel angesichts des Deutschen Ordens bleibt vor diesem Hintergrund offen. Es ist offensichtlich, dass die Domherren der inkorporierten Kapitel die Kanzleiarbeit für den Orden leisteten. Ist aber Diplomatie mit Spiritualität gleichberechtigt? Am Ende des I 4. Jh.s nahm die kirchliche Hierarchie an der Strömung der böhmischen devotio moderna teil. $\mathrm{Ob}$ man dieses Phänomen als eine typische Haltung aller Ordenspriester dieser Zeit betrachten kann, lasse ich offen. Im Lichte der Forschungen von Stefan Kwiatkowski war für die Ordensbrüder sicher die via antiqua charakteristisch..$^{1}$ Zwar war das Domkapitel von Pomesanien bis zum Ende des Ordenslandes dem Deutschen Orden nah und treu, ${ }^{72}$ was auch die sehr späte Ikonographie bezeugt. ${ }^{73}$ Während des Pontifikats der Bischöfe Johannes Mönch und Johannes Ryman

70 Cod. Sermones de tempore, I408, Toruń, Biblioteka Uniwersytecka, Rps 48/III; Katalog, hrsg. v. Czyżak, 202-207.

${ }_{71}$ Stefan Kwiatkowski, Zakon Niemiecki w Prusach a umystowość średniowieczna. Scholastyczne rozumienie prawa natury a etyczna i religijna świadomość krzyżaków do okoto $1420 \mathrm{r}$. (Toruń: Wydawnictwo Uniwersytetu Mikołaja Kopernika, I 998); vgl. auch frühere Analyse von Karol Górski, "Religijność Krzyżaków a klimat kulturalny," Przegląd Historyczny 75, H. 2 (1984): 249-255.

72 Im Vergleich zu anderen inkorporierten Domkapiteln war das Kapitel in Marienwerder wenigsten autonom, obwohl die Tätigkeit um 1400 eine besondere Phase in dessen Geschichte bildete: Jarosław Wenta, Studien über die Ordensgeschichtsschreibung am Beispiel Preußens (Toruń: Wydawnictwo Uniwersytetu Mikołaja Kopernika, 2000), 172, I 76-1 78.

73 Die Bildnisse der drei Hochmeister im Marienwerderer Hochchor (wahrscheinlich Stiftung von Bischof Johannes IV Kierstani oder Hiob Dobeneck) sind dafür symptomatisch, vgl. Raczkowski, "Późnogotyckie malowidła", 203. 
kann man aber eine steigende Distanzierung vom Orden beobachten, worauf auch Kwiatkowski in seinen Studien hingewiesen hat. ${ }^{74}$ Im Falle der Ecclesia Culmensis hat die Krise sogar zur Abtrennung eines ganzen Kapitels geführt; schon früher kann man in der Synodalpredigt Marienaus Kritik am Orden finden. ${ }^{75}$

Meiner Meinung nach ist um I 400 die Spiritualität der kirchlichen Hierarchie in Preußen außerhalb der Tradition und Mentalität des Deutschen Ordens zu verstehen (im pomesanischen Gebrauchkodex 3/I stehen am Anfang zwar die Deutschordensstatuten, dann aber kommen die mystischen Texte). Die Schriften von Johannes Marienwerder sollte man eher nicht als einen Teil der Ordensliteratur betrachten ${ }^{76}$ weil er seine Ausbildung vor seinem Eintritt in den Orden erhielt und ein Teil seines Erbes schon in Prag geschrieben wurde. Auch die späteren Dorotheenschriften hat er im Austausch mit seinen Prager Meister Heinrich von Oyta verfasst. ${ }^{77}$ Die via moderna war dem Deutschen Orden (als einer konservativen Korporation) fremd: Der religiöse Weg ins Spätmittelalter wurde um I 400 von den Kapiteln unabhängig vom Deutschen Orden bestimmt.

74 Stefan Kwiatkowski, Klimat religijny w diecezji pomezańskiej u schytku XIV wieku i w pierwszych dziesięcioleciach XV wieku, Roczniki Towarzystwa Naukowego w Toruniu 84/ I (Toruń: Towarzystwo Naukowe, I990), 88; ders., "Stosunek zakonu krzyżackiego do diecezji chełmińskiej," in $Z$ przesztości diecezji chetmińskiej I243-I992: materiaty z konferencji naukowej w Toruniu 6 XI I993 r., hrsg. v. Marian Biskup (Toruń: Towarzystwo Naukowe, I 994), 7-20.

75 Für Metzel-Reuters war das ein Argument gegen Identifizierung des Predigers mit dem Kulmer Bischof: Arno Mentzel-Reuters, "Preußische Diözesanstatuten und Reformen im Deutschen Orden," in Von der Ordnung zur Norm: Statuten in Mittelalter und Früher Neuzeit, hrsg. v. Gisela Drossbach (Paderborn: Schöningh, 20 I o), 6 I-64; anders aber: Sumowski, "Jan Marienau," 50I-5I9.

${ }^{76}$ Wenta, Studien, 177-178, 23 1-234; Arno Mentzel-Reuters, Arma spiritualia: Bibliotheken, Bücher und Bildung im Deutschen Orden, Beiträge zum Buch- und Bibliothekswesen 47 (Wiesbaden: Harrassowitz, 2003), 90-96 (Johannes Marienwerder ist hier als "ein typischer Vertreter des Priesterschafts des Deutschen Ordens" bezeichnet: ebd., 9 I).

77 Borzyszkowski, "Problematyka filozoficzna," (1 968), i 35. 


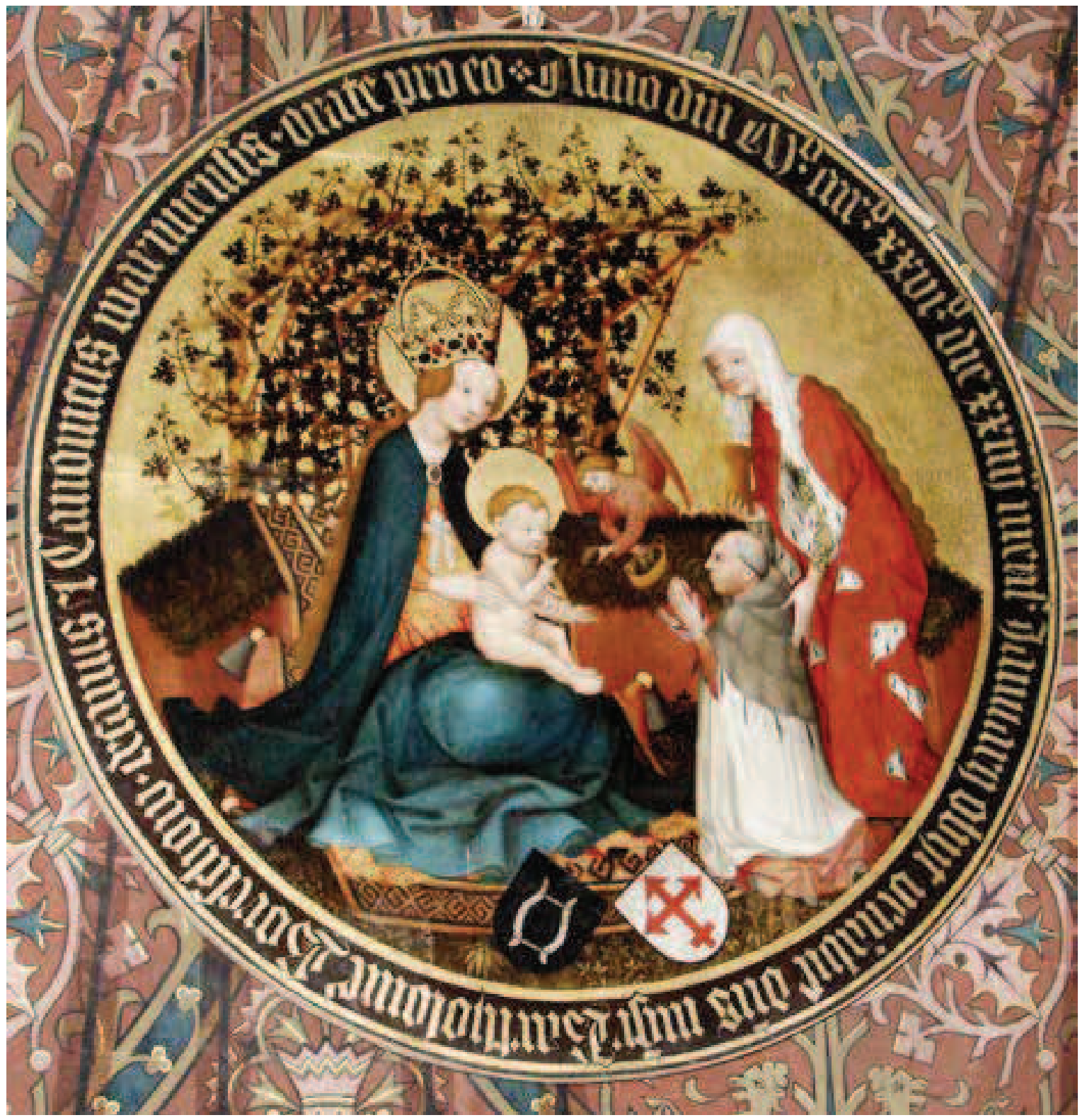

Abb. I: Frauenburg (Frombork), Dom. Epitaph von Bartholomeus Boreschow, vor I 426. Foto Juliusz Raczkowski. 


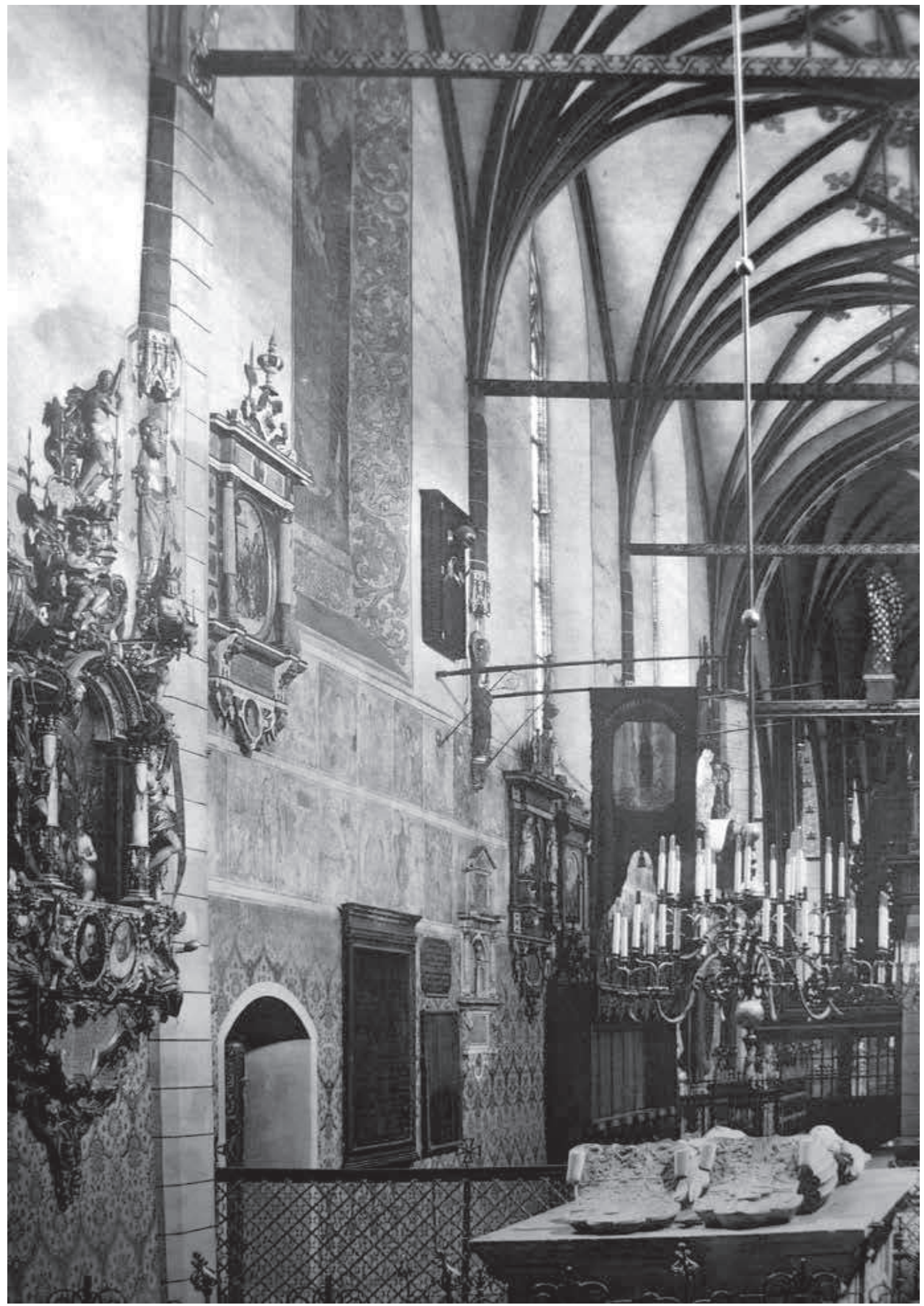

Abb. 2: Königsberg/Pr. (Kaliningrad), Chor des Domes - Inneraum vor I 945. Nach: Dethlefsen, Die Domkirche, Taf. 3. 


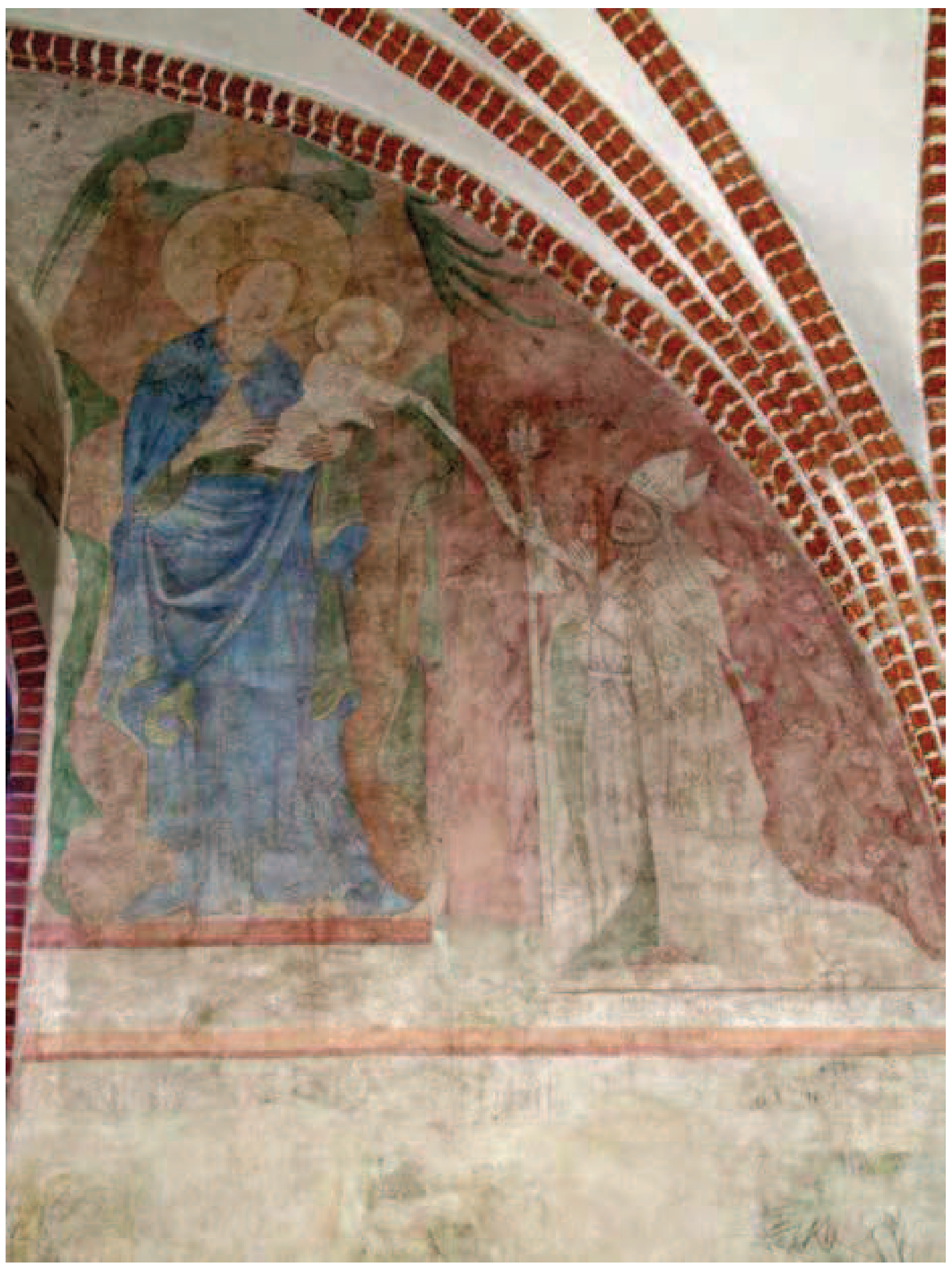

Abb. 3: Heilsberg (Lidzbark Warmiński), Bischofsschloss Wandmalerei in Sommerremter, I 4./ I s. Jh.s, Detail: Bischof Anselm vor Maria. Foto Juliusz Raczkowski. 


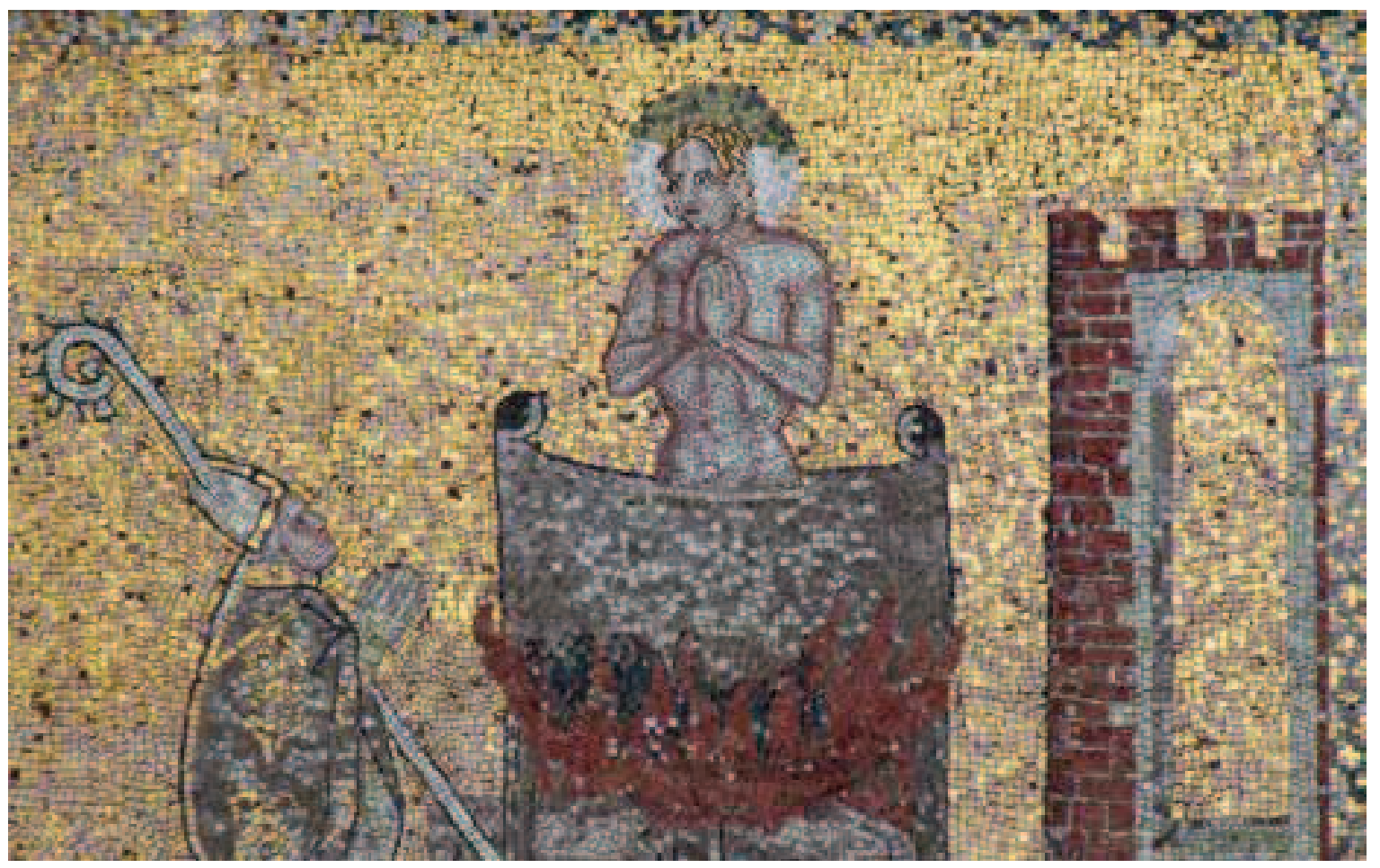

Abb. 4: Marienwerder (Kwidzyn), Dom. Mosaik Johannes Mönchs über dem Südportal, Ende des I 4. Jh.s. Foto Monika Jakubek-Raczkowska.

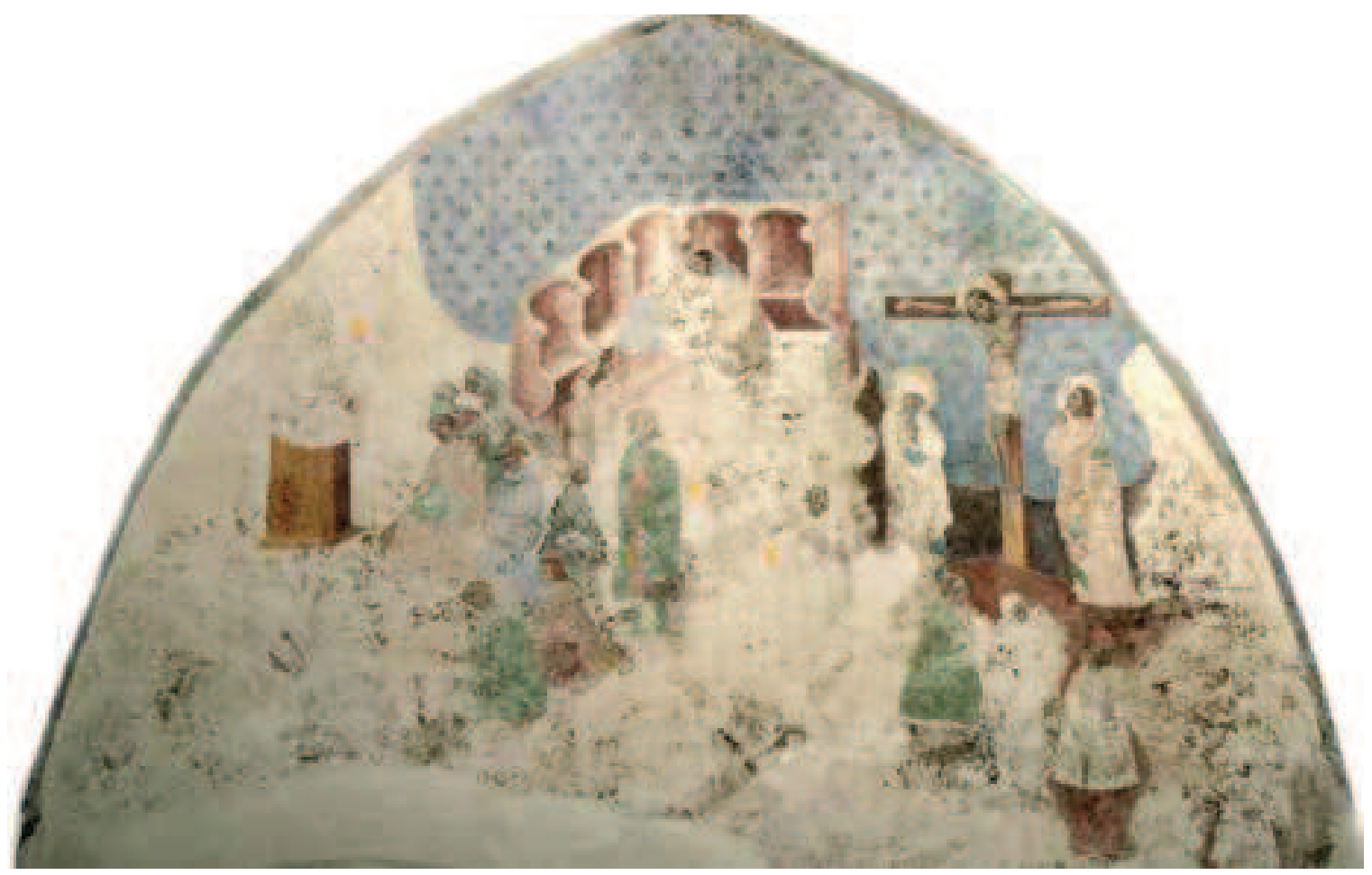

Abb. 5: Heilsberg (Lidzbark Warmiński), Bischofsschloss. Wandmalerei im westlichen Flügel des Kreuzganges, Ende des I4. Jh.s, Darstellung der bischöflichen Evangelisierungmission. Rekonstruktion von Ryszard Żankowski, nach Żankowski, "Badania i rekonstrukcja”, I I I . 


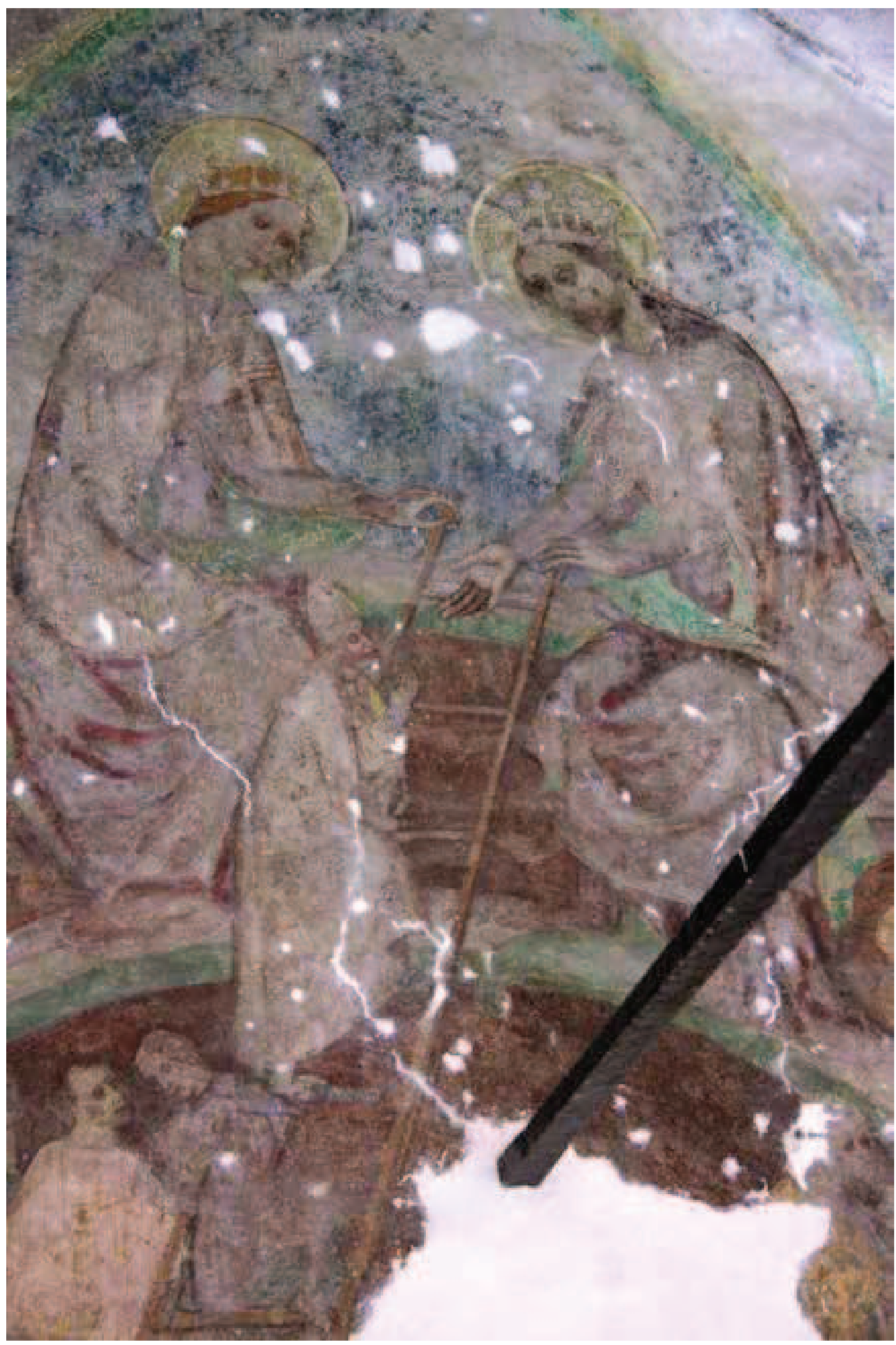

Abb. 6: Heilsberg (Lidzbark Warmiński), Bischofsschloss. Wandmalerei im westlichen Flügel des Kreuzganges, Ende des i 4. Jh.s, Darstellung des Bischofs, das Volk in den Himmel führend, Detail. Foto Juliusz Raczkowski. 


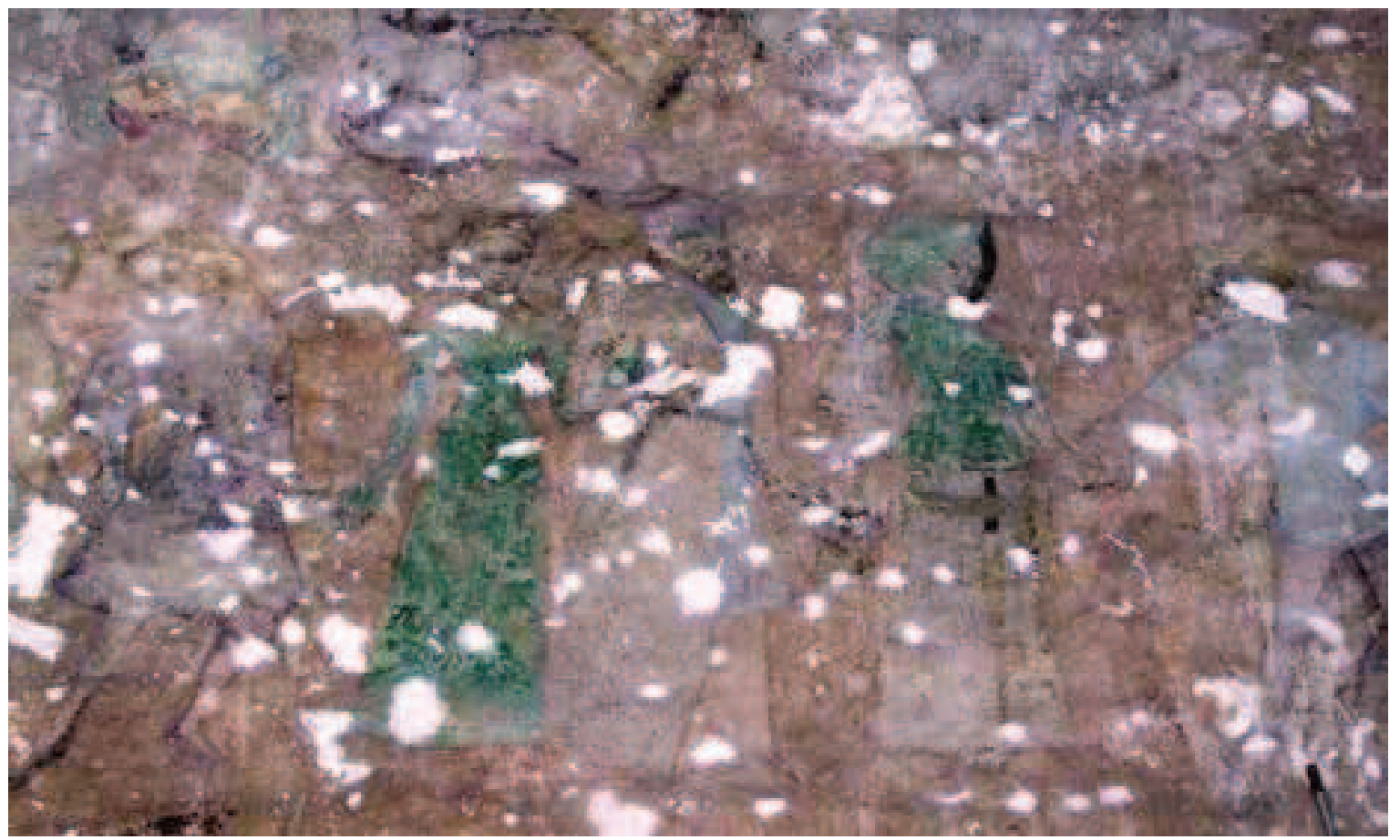

Abb. 7: Heilsberg (Lidzbark Warmiński), Bischofsschloss. Wandmalerei im westlichen Flügel des Kreuzganges, Ende des I 4. Jh.s, Darstellung der verdammten Laien, Detail: die Tanzenden. Foto Monika Jakubek-Raczkowska.

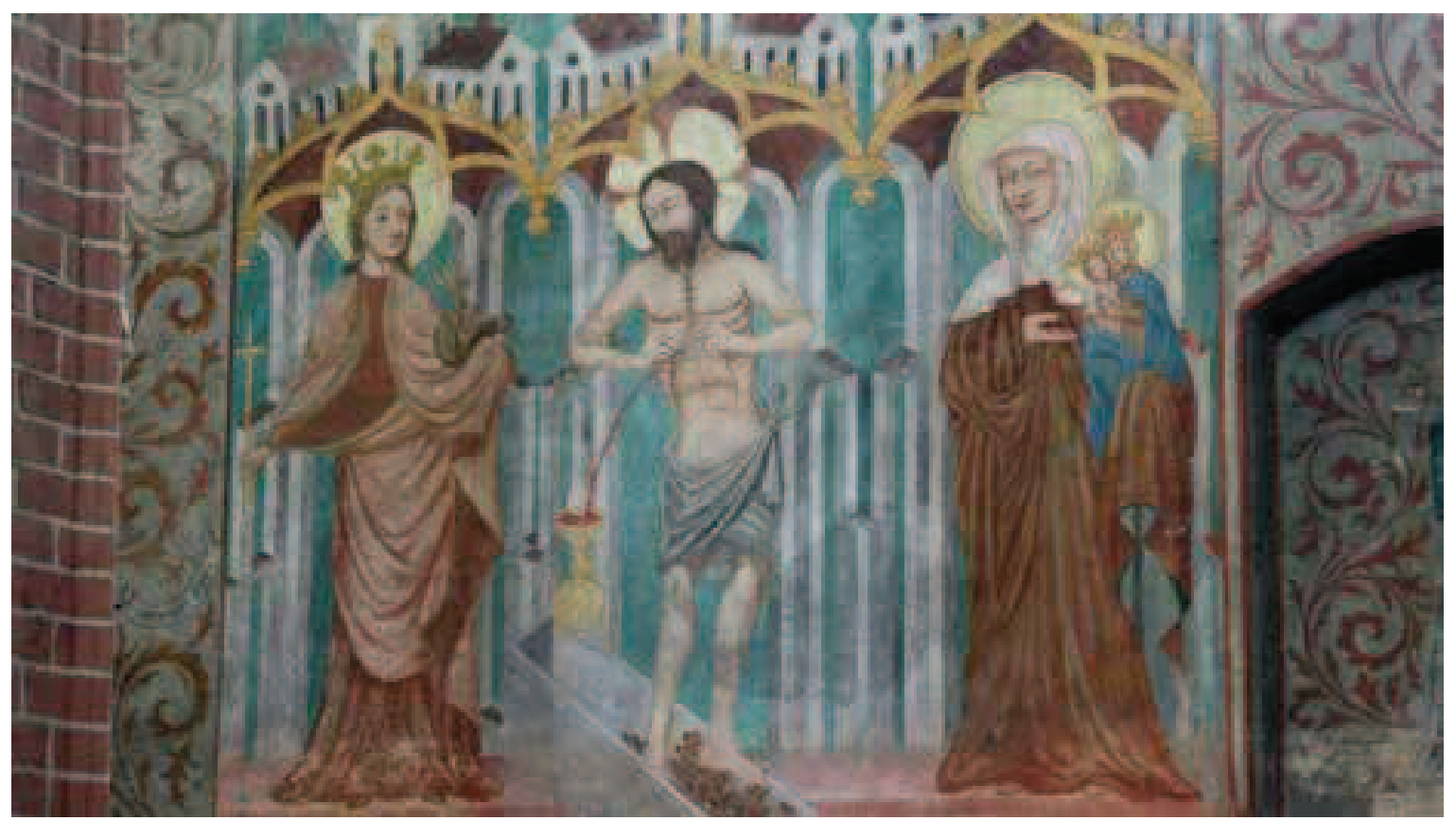

Abb. 8: Marienwerder (Kwidzyn), Dom. Wandmalereizyklus im nördlichen Seitenschiff, Altarbild mit Schmerzensmann. Foto Juliusz Raczkowski. 


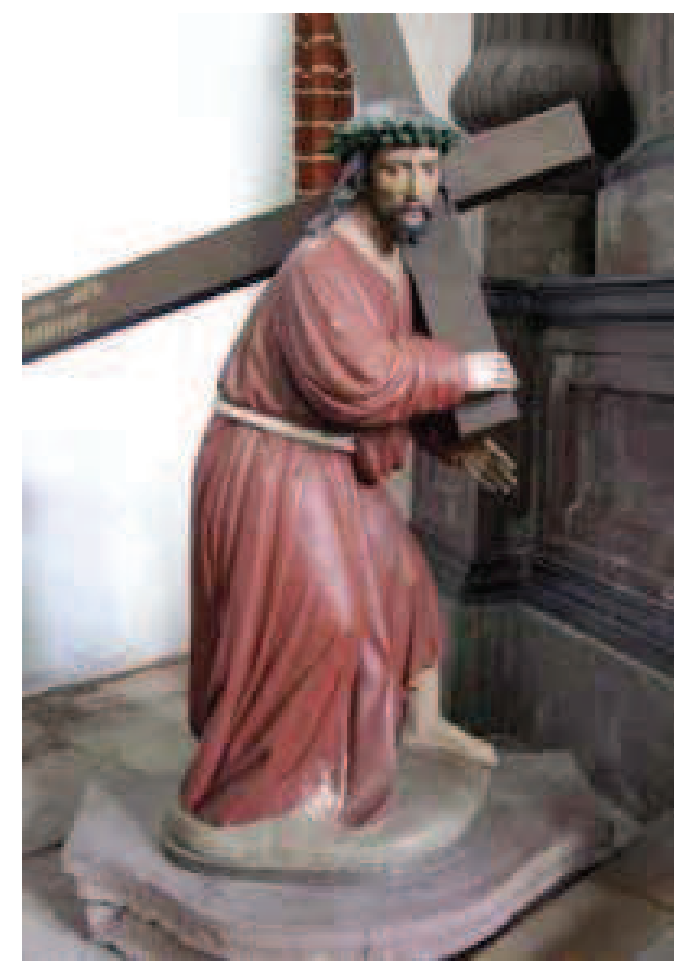

Abb. 9: Kulmsee (Chęmża), Dom. Kreuztragender Christus, vor i425. Foto Monika Jakubek-Raczkowska.

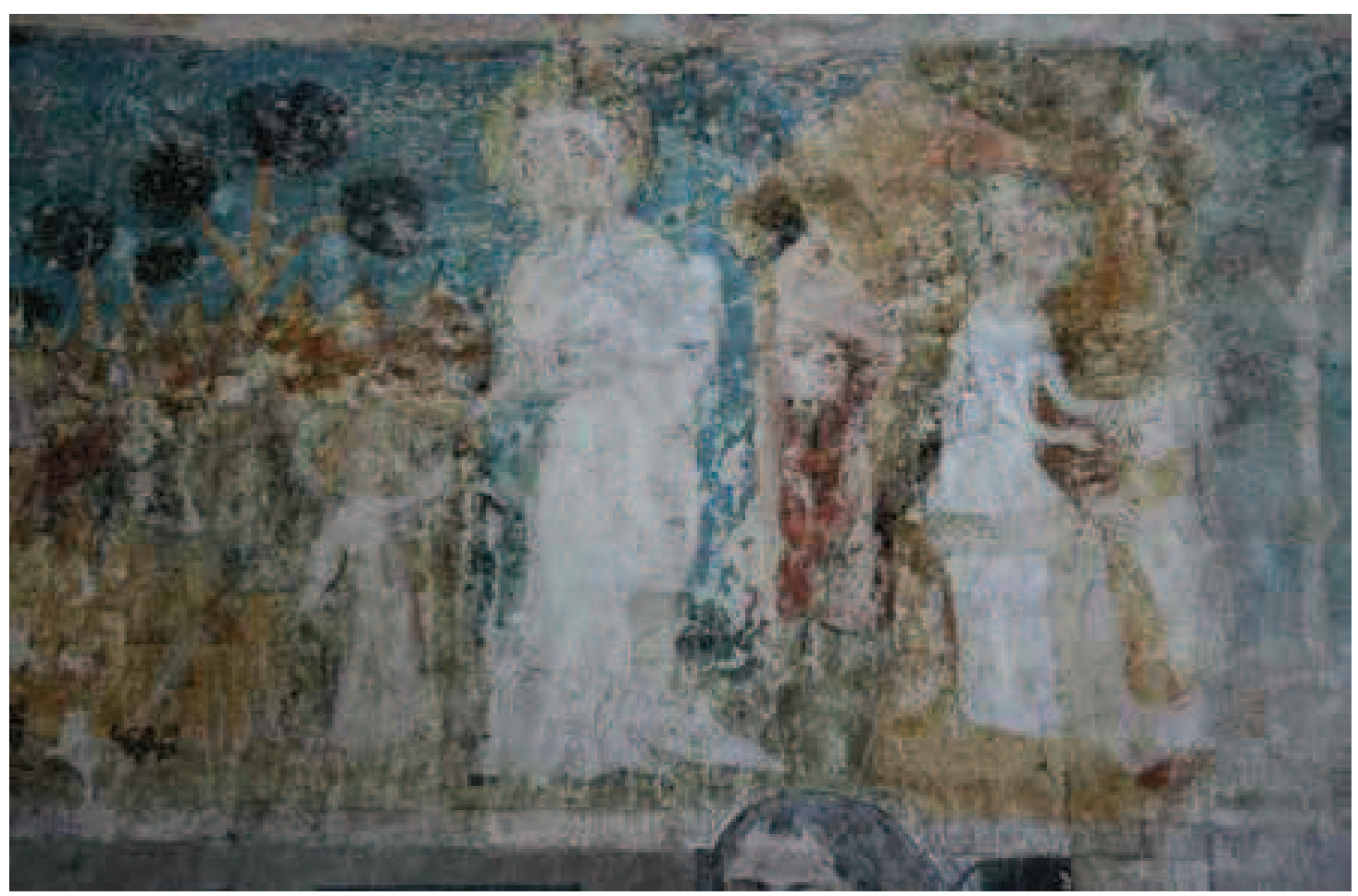

Abb. i o: MARIEnwerder (Kwidzyn), Dom, Domherrenchor ("obere Kirche”). Freigelegte Fragmente von Wandmalereizyklus, Ende des i 4. Jh.s, Detail, Infantia Christi. Foto Juliusz Raczkowski. 




Abb. I I : Gebrauchskodex von Johannes Albrechtau, Silva Rerum, um I390, Toruń, Biblioteka Uniwersytecka, Rps 52 /III - Skizze mit Schmerzensmann. Foto Monika Jakubek-Raczkowska. 


\section{PRIMARY SOURCES}

Codex Gertrudianus / Psalterium Egberti. Zugegriffen am 8. November 2018. http:// www.librideipatriarchi.it/en/egberts-psalter-codex-gertrudianus/

Toruń, Biblioteka Uniwersytecka, Rps: 3/I, 9/I, $38 /$ III, 3 I /III, 35/III, 48/III, 52/III, 75 /III.

Codex Diplomaticus Prussicus. Urkunden-Sammlung zur ältern Geschichte Preusens aus dem Königl. Geheimen Archiv zu Königsberg nebst Regesten. Bd. III. Herausgegeben von Johannes Voigt. Königsberg: Gebrüdern Vornträger, I 848.

“Die pomesanischen Diözesansynoden." Pastoralblatt für die Diözese Ermland 30, H. 3 (1 898$): 50-59$.

Jan z Kwidzyna. "Prolog do Expositio symboli apostolorum." Herausgegeben von Marian Borzyszkowski. Textus et studia. Historiam theologiae in Polonia excultae spectantia $\mathrm{II} / 2$ = Materiały do historii teologii średniowiecznej w Polsce 2, 5-38. Warszawa: Akademia Teologii Katolickiej, 1974.

Johannes Marienau. "Sermo in. conc. prov. Elbingensi (Potentia patris regat...)." Herausgegeben von Otto Günther. In Otto Günther, "Eine Predigt vom preußischen Provinzialkonzil in Elbing 1427 und die Ermahnung des Carthäusers." Zeitschrift des Westpreußischen Geschichtsvereins 59 ( I 919): 69- I I I (Quellenedition: 94- I I I).

Johannes Marienwerder. "Das leben der seligen Dorothea von Preussen.” Nach der deutschen Lebensbeschreibung des Johannes Marienwerders in neuerer Schriftsprache herausgegeben von Franz Hipler, Zeitschrift für die Geschichte und Alterstumskunde Ermland Io (1 894): 297-504.

Johannes Marienwerder. Liber de festis Magistri Johannes Marienwerder. Offenbarungen der Dorothea von Montau. Herausgegeben von Annelise Triller, unter Mitwirkung Ernst Borchert, nach Vorarbeiten von Hans Westpfahl. Köln-Weimar-Wien: Böhlau, I 992.

Johannes Marienwerder. Septililium Beatae Dorotheae Montovensis auctore Joanne Marienwerder. Herausgegeben von Franciscus Hipler. Bruxelles: Analecta Bollandiana, i 885 .

Johannes Marienwerder. Vita Dorotheae Montoviensis Magistri Johannis Marienwerder. Herausgegeben von Hans Westpfahl, unter Mitwirkung Anneliese Triller. KölnGraz: Böhlau, 1964.

Johannes Merkelin. Liber de instructione simplicium sacerdotium. Tl. I-2. Herausgegeben von Marian Borzyszkowski. Textus et studia. Historiam theologiae in Polonia excultae spectantia XII/ I -2. Warszawa: Akademia Teologii Katolickiej, 1982.

Urkundenbuch des Bisthums Culm. Bd. I, Das Bisthum unter dem Deutschen Orden I243- I466. Herausgegeben von Carl Peter Woelky. Neues Preussisches Urkundenbuch. Westpreussischer Theil, II. Abtheilung: Urkunden der Bisthümer, Kirchen und Klöster I. Danzig: Commissionsverlag von Theodor Bertling, I 885.

\section{SECONDARY SOURCES:}

Bielak, Włodzimierz. Devotio moderna w polskich traktatach duszpasterskich powstatych do potowy XV wieku. Lublin: Wydawnictwo KUL, 2002. 
Biskup, Radosław. Das Domkapitel von Samland (1285-1525). Toruń: Wydawnictwo Naukowe Uniwersytetu Mikołaja Kopernika, 2007.

Borzyszkowski, Marian. "Wczesny humanizm w Czechach a devotio moderna." Rezension von Frühhumanismus. Seine Entwicklung in Böhmen und deren europäische Bedeutung für die Kirchenreformbestrebungen im I4. Jahrhundert von Edouard Winter. Studia Warminskie 4 (1967): 359-362.

Borzyszkowski, Marian. "Problematyka filozoficzna i teologiczna w twórczości Jana z Kwidzyna (1 343- I 4 I 7)." Studia Warminskie 5 (I 968): I I I - I 99.

Borzyszkowski, Marian. "Problematyka filozoficzna i teologiczna w twórczości Jana z Kwidzyna ( I 343 - I 4 I 7). Dokończenie.” Studia Warmińskie 6 (I 969): 8 5- I 7 I.

Borzyszkowski, Marian. "Komentarz do Prologu Expositio Symboli Apostolorum Jana z Kwidzyna." In Jan z Kwidzyna. "Prolog do Expositio symboli apostolorum," herausgegeben von Marian Borzyszkowski. Textus et studia. Historiam theologiae in Polonia excultae spectantia II/2 = Materiały do historii teologii średniowiecznej w Polsce 2, 39-6 I. Warszawa: Akademia Teologii Katolickiej, 1974.

Chodyński, Antoni Romuald. "Epitafium Bartholomeusa Boreschowa, ok. poł. XV w." In Fundacje artystyczne na terenie państwa krzyżackiego w Prusach. Katalog wystawy w Muzeum Zamkowym w Malborku 25 czerwca - I2 września 2oIo roku. Bd. I, Katalog wystawy, herausgegeben von Barbara Pospieszna, I 92-1 93. Malbork: Muzeum Zamkowe, 20 I 0.

Chodyński, Antoni Romuald. "Portret czy wizerunek paradygmatyczny. Forma i symbolika epitafium Bartholomeusa Boreschowa z około połowy XV wieku." Studia Zamkowe 6 (201 2): 27-43.

Czyżak, Marta. "Medieval manuscripts as ego-documents on examples of the prayer book of Wikbold Dobilstein and the biblical-moralistic collection of Johann Albrechtau in the 4th quarter of the I 4 th century." In Editionswissenschaftliches Kolloquium 2013. Neuere Editionen der sogenannten "Ego-Dokumente" und andere Projekte in den Editionswissenschaften, herausgegeben von Helmut Flachenecker, Janusz Tandecki und Krzysztof Kopiński. Publikacje Niemiecko-Polskiej Grupy Dyskusyjnej do Spraw Edycji Źródeł 7, i 8-25. Toruń: Towarzystwo Naukowe, 20 I 5.

Czyżak, Marta. "Interdyscyplinarne prace badawcze nad Katalogiem rękopisów średniowiecznych Biblioteki Uniwersyteckiej w Toruniu." In Stare i nowe dziedzictwo Torunia, Bydgoszczy i regionu, herausgegeben von Juliusz Raczkowski und Monika Jakubek-Raczkowska. Studia i materiały z dziedzictwa kulturowego Torunia i regionu 2, 95- I06. Toruń: Wydawnictwo Naukowe Uniwersytetu Mikołaja Kopernika, 20 I 7. Dekarli, Martin. "Henry Totting of Oyta and the Prague Nominalis Schola Communis between I 366- I 409: A Preliminary Draft." In The First Decades of Prague University: Transforming Intellectual Space in I4th Century Central Europe, herausgegeben von Jan Odstrčilík, Francesca Battista, und Riccardo Burgazzi, 53-70. Prague: Karolinum Press, 2016.

Dethlefsen, Richard. Die Domkirche in Königsberg i. Pr. nach ibrer jüngsten Wiederherstellung. Berlin: Wasmuth, i 9 I 2. 
Die Bau- und Kunstdenkmäler der Provinz Westpreußen. Bearbeitet von Johannes Heise. Bd. I I, Die Bau- und Kunstdenkmäler des Kreises Marienwerder östlich der Weichsel. Danzig: Commissions-Verlag, i 898.

Die Domkapitel des Deutschen Ordens in Preußen und Livland. Herausgegeben von Radosław Biskup und Mario Glauert. Zeitschrift für die Geschichte und Altertumskunde Ermlands, Beiheft 17. Münster: Aschendorff, 2004.

Die „Neue Frömmigkeit“ in Europa. Herausgegeben von Marek Derwich und Martial Staub. Veröffentlichungen der Max-Planck-Institut für Geschichte 205. Göttingen: Vandenhoeck \& Ruprecht, 2004.

Domasłowski, Jerzy. "Dwa przedstawienia średniowiecznego traktatu teologicznego w pomorskim malarstwie ściennym.” Rocznik Olsztyński I 6 (1989): 27 I-292.

Domasłowski, Jerzy. "Gotyckie malowidła ścienne krużganku zamku biskupiego w Lidzbarku Warmińskim i ich europejski kontekst.” In Zamek malowany. Ratunkowe prace konserwatorskie krużganków zamku lidzbarskiego, herausgegeben von Janusz Cygański, 35-59. Olsztyn: Muzeum Warmii i Mazur, 20 I I.

Dygo, Marian. "O kulcie maryjnym w Prusach Krzyżackich w XIV-XV wieku." Zapiski Historyczne 52, H. 2 (1987): 5-36.

Gerwing, Manfred. “...state in fidevera, viriliteragite, omniavestrain caritatefiant. Zum dreifachen Weg im Malogranatum.” In Die „Neue Frömmigkeit“ in Europa, herausgegeben von Marek Derwich und Martial Staub. Veröffentlichungen der Max-Planck-Institut für Geschichte 205, 85-I I 0. Göttingen: Vandenhoeck \& Ruprecht, 2004.

Glauert, Mario. Das Domkapitel von Pomesanien (1284-1527). Toruń: Wydawnictwo Naukowe Uniwersytetu Mikołaja Kopernika, 2003.

Grabowska-Lysenko, Alicja. "Ikonografia bł. Doroty z Mątów Wielkich.” In Kwidzyńska rekluza. Uniwersalne i regionalne przejawy kultu bt. Doroty z Mątów, herausgegeben von Janusz Hochleitner, I75-r 94. Kwidzyn: Muzeum w Kwidzynie, 20 I 4.

Günther, Otto. "Eine Predigt vom preußischen Provinzialkonzil in Elbing I 427 und die Ermahnung des Carthäusers." Zeitschrift des Westpreußischen Geschichtsvereins 59 ( I 9 I 9): 69-I I I.

Head, Thomas. "Art and Artifice in Ottonian Trier." Gesta 36, H. I (1 997): 65-82.

Helms, Simon. Luther von Braunschweig. Der Deutsche Orden in Preußen zwischen Krise und Stabilisierung und das Wirken eines Fürsten in der ersten Hälfte des 14. Jahrbunderts. Quellen und Studien zur Geschichte des Deutschen Ordens 67. Marburg: N. G. Elwert Verlag, 2009.

Hess, Cordelia. Heilige machen im spätmittelalterlichen Ostseeraum. Die Kanonisationsprozesse von Birgitta von Schweden, Nikolaus von Linköping und Dorothea von Montau. Europa im Mittelalter. Abhandlungen und Beiträge zur historischen Komparatistik I I. Berlin: De Gruyter, 2008.

Hipler, Franz. Bibliotheca Warmiensis oder Literaturgeschichte des Bistums Ermland. Bd. I, Abriss der Ermländischen Literaturgeschichte nebst dem Spicilegium Copernicanum. Monumenta Historiae Warmiensis IV. Braunsberg-Leipzig: Eduard Peter, I 872. 
Jäggi, Carola. "Ravenna in the Sixth Century: the Archaeology of Change”. In Ravenna. Its Role in Earlier Medieval Change and Exchange, herausgegeben von Judith Herrin und Jinty Nelson, 87-1 09. London: University of London, Institute of Historical Research, 2016.

Jakubek-Raczkowska, Monika. "Amoris saggitae et spicula. Cielesne aspekty mistyki bł. Doroty z Mątów - próba reinterpretacji." Studia Elbląskie I 5 (20 I 4): I 65- I 87.

Jakubek-Raczkowska, Monika. "Mentis oculos levavit. Obrazowe aspekty mistyki Doroty z Mątów." Studia Elbląskie I 4 (20 I 3): 289-306.

Jakubek-Raczkowska, Monika. „Tu ergo flecte genua tua.” Sztuka a praktyka religijna świeckich $w$ diecezjach pruskich państwa zakonu krzyżackiego do potowy XV wieku. Pelplin: Bernardinum, 20 I 4.

Jakubek-Raczkowska, Monika, und Juliusz Raczkowski. "Średniowieczny wystrój zespołu Wielkiego Refektarza na Zamku Średnim w Malborku.” In Wielki Refektarz na Zamku Średnim w Malborku. Dzieje - wystrój - konserwacja, herausgegeben von Janusz Trupinda, 4I-80. Malbork: Muzeum Zamkowe, 20 I 0.

Jarzebowski, Marc. Die Residenzen der Preußischen Bischöfe bis I525. Toruń: Wydawnictwo Naukowe Uniwersytetu Mikołaja Kopernika, 2007.

Katalog rękopisów średniowiecznych Biblioteki Uniwersyteckiej w Toruniu. Herausgegeben von Marta Czyżak, unter Mitwirkung von Monika Jakubek-Raczkowska und Arkadiusz Wagner. Toruń: Wydawnictwo Naukowe Uniwersytetu Mikołaja Kopernika, 2016.

Krajniak, Radosław. "Prałaci kapituły katedralnej w Chełmży w okresie krzyżackim (do I 466r.)." In Kościót i duchowienstwo w średniowiecznej Polsce i na obszarach sasiednich, herausgegeben von Radosław Biskup und Andrzej Radzmiński. Ecclesia clerusque temporibus medii aevi 3, 73- I 17. Toruń: Wydawnictwo Naukowe Uniwersytetu Mikołaja Kopernika, 20 I 3.

Krajniak, Radosław. Duchowieństwo kapituty katedralnej w Chetmży do I 466 roku: studium prozopograficzne. Toruń-Łysomice: Europejskie Centrum Edukacyjne, 20 I 3.

Krajniak, Radosław. "Z badań nad biografiami członków warmińskiej kapituły katedralnej w pierwszym okresie jej funkcjonowania (do połowy XIV wieku)." Zapiski Historyczne 80 , H. I (201 5): 65-83.

Krzyżaniakowa, Jadwiga. "Henryk Totting z Oyty i jego prascy uczniowie.” Roczniki Historyczne 6i (1995): 87- i 09.

Kwiatkowska, Wiesława. "Średniowieczna biblioteka klasztoru franciszkanów w Toruniu." Folia Toruniensia I (2000): 9-30.

Kwiatkowski, Stefan. Klimat religijny w diecezji pomezańskiej uschytkuXIV wieku i wpierwszych dziesięcioleciach XV wieku. Roczniki Towarzystwa Naukowego w Toruniu 84/ I. Toruń: Towarzystwo Naukowe, I 990.

Kwiatkowski, Stefan. Zakon Niemiecki w Prusach a umystowość średniowieczna. Scholastyczne rozumienie prawa natury a etyczna i religijna świadomość krzyżaków do okoto I420 r. Toruń: Wydawnictwo Uniwersytetu Mikołaja Kopernika, I 998. 
Kwiatkowski, Stefan. "Wpływ doktryny Jana Taulera na hagiograficzną sylwetkę Doroty z Mątowów w piśmiennictwie Jana z Kwidzyna.” In Balticum. Studia z dziejów polityki, gospodarki i kultury XII-XVII wieku ofiarowane Marianowi Biskupowi w siedemdziesiata rocznice urodzin, herausgegeben von Zenon Hubert Nowak, I 89-196. Toruń: Wydawnictwo Towarzystwa Naukowego, 1992.

Labuda, Adam S. "Malarstwo tablicowe państwa krzyżackiego drugiej połowy XIV wieku." In Jerzy Domasłowski, Alicja Karłowska-Kamzowa, und Adam S. Labuda, Malarstwo gotyckie na Pomorzu Wschodnim, 66-90. Warszawa-Poznań: Państwowe Wydawnictwo Naukowe, I 990.

Majoch, Sławomir. "Rzeźba Chrystusa dźwigającego krzyż z konkatedry w Chełmży. Forma i funkcja." Rocznik Muzeum Okregowego w Toruniu I 2 (2003): 72-91.

Mentzel-Reuters, Arno. Arma spiritualia: Bibliotheken, Bücher und Bildung im Deutschen Orden. Beiträge zum Buch- und Bibliothekswesen 47. Wiesbaden: Harrassowitz, 2003.

Mentzel-Reuters, Arno. "Preußische Diözesanstatuten und Reformen im Deutschen Orden." In Von der Ordnung zur Norm: Statuten in Mittelalter und Früher Neuzeit, herausgegeben von Gisela Drossbach, 55-70. Paderborn: Schöningh, 20 I 0.

Nechutová, Jana. "Reform- und Bußpreidger von Waldhauser bis Hus." In Kirchliche Reformimpulse des I4./I5. Jahrbunderts in Ostmitteleuropa, herausgegeben von Winfried Eberhard und Franz Machilek, 239-254. Köln-Weimar-Wien: Böhlau, 2006.

Nowiński, Janusz. Ars Eucharistica. Idee, miejsca i formy towarzyszace przechowywaniu eucharystii w sztuce wczesnochrześcijańskiej i średniowiecznej. Warszawa: Neriton, 2000.

Oliński, Piotr. "Bücherliste aus dem Inventar des St. Elisabeth-Hospitals in Danzig. Analyse eines Quellenfragments." In Quellen kirchlicher Provenienz. Neue Editionsvorhaben und aktuelle EDV-Projekte, herausgegeben von Helmut Flachenecker und Janusz Tandecki, I 6 I-I 7 I. Toruń: Towarzystwo Naukowe, 20 I I.

Paravicini, Werner. Die Preußenreisen des europäischen Adels. Tl. I. Beihefte der Francia I 7/I. Sigmaringen: Deutsches Historisches Institut Paris, I 988.

Päsler, Ralf. "Ein neuer Textzeuge des 'Granum Sinapis' aus der Königsberger Dombibliothek." Zeitschrift für deutsches Altertum und deutsche Literatur I 36 (2007): 58-67.

Pilecka, Elżbieta. "Splendor władzy w średniowiecznej rezydencji biskupów warmińskich." In Sztuka w kręgu wtadzy. Materiaty LVII Ogólnopolskiej Sesji Naukowej SHS poświęconej pamięci Profesora Szczęsnego Dettloffa (I987-196I) w I3o rocznicęurodzin, Torun I3-Is listopada 2008, herausgegeben von Elżbieta Pilecka und Katarzyna Kluczwajd, 53-75. Warszawa: Stowarzyszenie Historyków Sztuki, 2009.

Pospieszna, Barbara. "Z piasku i popiołu Kegin unser libin frouwin bilde. Sztuka mozaiki w państwie zakonnym w Prusach." In Monumentalna figura Madonny na kościele NMP w Malborku. Konteksty historyczne, artystyczne i konserwatorskie, herausgegeben von Janusz Hochleitner, 95-i I o. Malbork: Muzeum Zamkowe, 20 I 5.

Raczkowski, Juliusz. “Die Marien-Aussage der Chorausstattung des Doms zu Königsberg/ Pr. vor dem Hintergrund der Ideologie des Deutschen Ordens in Preußen." In Terra Sanctae Mariae. Mittelalterliche Bildwerke der Marienverehrung im Deutschordensland 
Preußen, herausgegeben von Gerhard Eimer, Ernst Gierlich, Matthias Müller, und Kazimierz Pospieszny. Kunsthistorische Arbeiten der Kulturstiftung der deutschen Vertriebenen 7, I I 9-I 35. Bonn: Kulturstiftung der deutschen Vertriebenen, 2009.

Raczkowski, Juliusz. "Malowidła ścienne w katedrze w Kwidzynie, 4 ćw. XIV w." In Fundacje artystyczne na terenie państwa krzyżackiego w Prusach. Katalog wystawy w Muzeum Zamkowym w Malborku 25 czerwca-I2 września 20 Io roku. Bd. I, Katalog wystawy, herausgegeben von Barbara Pospieszna, 167. Malbork: Muzeum Zamkowe w Malborku, 20 I 0.

Raczkowski, Juliusz. "Medieval murals recently uncovered in the chamber above the gate of the castle of the chapter of the diocese of Pomesania in Kwidzyn: Preliminary analysis: iconography, style, dating and functional role of the chamber." Ordines Militares Colloquia Torunensia Historica. Yearbook for the Study of the Military Orders 22 (2017): 287-304.

Raczkowski, Juliusz. Monumentalne zespoty kolegium apostolskiego na terenie dawnego państwa zakonnego w Prusach. Pelplin: Bernardinum, 20 I 3.

Raczkowski, Juliusz. "Późnogotyckie malowidła w górnym chórze katedry kwidzyńskiej." Studia Zamkowe 2 (2006): I 8 5-204.

Raczkowski, Juliusz. "Problematyka konserwatorska malowideł w chórze katedry w Kwidzynie w kontekście historycznym oraz w świetle najnowszych odkryć.” In Studenci o konserwacji. Materiaty III Ogólnopolskiej Konferencji Naukowej Studentów Konserwacji Zabytków, Torun, 22-24 lutego 2001 r., herausgegeben von Tomasz Korzeniowski, I 5 I-I 64. Toruń: Koło Naukowe Studentów Konserwacji Dzieł Sztuki UMK, 200 I.

Radzimiński, Andrzej. “Z dziejów kształtowania i organizacji kapituł krzyżackich, Inkorporacje pruskich kapituł katedralnych do zakonu krzyżackiego.” In Zakon krzyżacki a spoteczeństwo państwa w Prusach, herausgegeben von Zenon Hubert Nowak. Roczniki Towarzystwa Naukowego w Toruniu 86/3, I23-135. Toruń: Towarzystwo Naukowe, I995.

Rode, Herbert. "Die Chorschrankenmalereien des Kölner Domes als Abbild des Sacrum Imperium." Kölner Domblatt 6-7 (1952): 20-38.

Rychterová, Paulína. "Konzepte der religiösen Erziehung der Laien in spätmittelalterlichen Böhmen. Einige Überlegungen zur Debatte über die sog. böhmische Devotio moderna." In Kirchliche Reformimpulse des I4./I5. Jahrbunderts in Ostmitteleuropa, herausgegeben von Winfried Eberhard und Franz Machilek, 2 I9-238. Köln-Weimar-Wien: Böhlau, 2006.

Samerski, Stefan. "Dorothea und kein Ende. Zur Prozess- und Kultgeschichte der hl. Dorothea von Montau." In Cura animarum. Seelsorge im Deutschordensland Preussen, herausgegeben von Stefan Samerski, 200-2 I 6. Köln-Weimar-Wien: Böhlau, 20 I 3. Seńko, Władysław, und Adam Ludwik Szafrański. "Mateusz z Krakowa i jego dzieło," In Mateusza z Krakowa Opuscula theologica dotyczace spowiedzi i komunii, herausgegeben von Władysław Seńko und Adam Ludwik Szafrański. Textus et studia. Historiam theologiae in Polonia excultae spectantia II/ I = Materiały do historii teologii średniowiecznej w Polsce I, 9-232. Warszawa: Akademia Teologii Katolickiej, I 974. 
Šmahel, František. "The Faculty of Liberal Arts 1367-1419." In František Šmahel, Die Prager Universität im Mittelalter / The Charles Univeristy in the Midlle Age. Gesammelte Aufsätze / Selectet Studies. Education and Society in the Middle Ages and Renaissance 28, 21 3-31 5. Leiden-Boston: Brill, 2007.

Sumowski, Marcin. "Jan Marienau biskup chełmiński ( 141 6-1 457)." Komunikaty Mazursko-Warmińskie 3/273 (201 I), 50 I-519.

Thérel, Marie-Louise. À lorigine du décor du portail occidental de Notre-Dame de Senlis: Le triomphe de la Vierge-Église. Sources historiques, littéraires et iconographiques. Paris: ed. Du C.N.R.S, 1984.

Wenta, Jarosław. Studien über die Ordensgeschichtsschreibung am Beispiel Preußens. Toruń: Wydawnictwo Uniwersytetu Mikołaja Kopernika, 2000.

Westpfahl, Hans. "Beichtbüchlein des Deutschen Ordens." In Acht Jahrhunderte Deutscher Orden in Einzeldarstellungen. Festschrift für Marian Tumler, herausgegeben von Klemens P. Wieser. Quellen und Studien zur Geschichte des Deutschen Ordens I, 24 I-268. Bad Godesberg: Verlag Wissenschaftliches Archiv, 1967.

Winter, Edouard. Frübhumanismus. Seine Entwicklung in Böhmen und deren europäische Bedeutung für die Kirchenreformbestrebungen im I4. Jabrbundert. Berlin: Akad. Verlag, 1964.

Żankowski, Ryszard. "Badania i rekonstrukcja wyglądu oraz treści przedstawień zniszczonych dekoracji malarskich z końca XIV wieku w krużgankach.” In Marcin Kozarzewski, Ryszard Żankowski und Adam Szweda, Polichromie krużganków zamku w Lidzbarku Warmińskim, 57-I I 3. Olsztyn: Muzeum Warmii i Mazur, 2016. 